\title{
Species Dynamics in Phytoplankton Blooms: Incomplete Mixing and Competition for Light
}

\author{
Jef Huisman, ${ }^{1,2, \star}$ Paul van Oostveen, ${ }^{3, \dagger}$ and Franz J. Weissing ${ }^{3}$
}

1. Biological Sciences, Stanford University, Stanford, California 94305-5020;

2. Center for Estuarine and Marine Ecology, CEMO-NIOO, P.O. Box 140, 4400 AC Yerseke, The Netherlands;

3. Department of Genetics, University of Groningen, P.O. Box 14, 9750 AA Haren, The Netherlands

Submitted September 22, 1998; Accepted February 23, 1999

ABSTRACT: With the eutrophication of many freshwaters and coastal environments, phytoplankton blooms have become a common phenomenon. This article uses a reaction-diffusion model to investigate the implications of mixing processes for the dynamics and species composition of phytoplankton blooms. The model identifies four key parameters for bloom development: incident light intensity, background turbidity, water column depth, and turbulent mixing rates. The model predicts that the turbulent mixing rate is a major determinant of the species composition of phytoplankton blooms. In wellmixed environments, the species with lowest "critical light intensity" should become dominant. But at low mixing rates, the species with lowest critical light intensity is displaced if other species obtain a better position in the light gradient. Instead of a gradual change in species composition, the model predicts steep transitions between the dominance regions of the various species. The model predicts a low species diversity: phytoplankton blooms in eutrophic environments should be dominated by one or a few species only. The model predictions are consistent with laboratory competition experiments and many existing field data. We recommend examining competition in phytoplankton blooms under well-controlled laboratory conditions, and we derive scaling rules that facilitate translation from the laboratory to the field.

Keywords: competition model, critical depth, critical turbulence, reaction-diffusion equation, population dynamics, resource competition.

* To whom correspondence should be addressed. Address for correspondence: Laboratory for Microbiology, University of Amsterdam, Nieuwe Achtergracht 127, 1018 WS Amsterdam, The Netherlands; e-mail: jef.huisman@chem.uva.nl.

${ }^{\dagger}$ Present address: Ministry of Foreign Affairs, P.O. Box 20061, 2500 EB Den Haag, The Netherlands.

Am. Nat. 1999. Vol. 154, pp. 46-68. (C) 1999 by The University of Chicago. 0003-0147/1999/15401-0004\$03.00. All rights reserved.
Most phytoplankton competition studies published to date have utilized well-mixed laboratory systems (Tilman 1977; Sommer 1985; Grover 1991; Rothhaupt 1996; Ducobu et al. 1998; Huisman et al. 1999a). In contrast, the word "plankton" stems from the Greek neuter of $\pi \lambda \alpha \gamma \kappa \tau \mathrm{os,}$ which means roaming or wandering (Hutchinson 1974). In many aquatic environments, phytoplankton species are not thoroughly mixed but slowly wander through the aquatic medium, often passively by turbulent diffusion and sinking and sometimes also actively by means of flagellae or buoyancy regulation (Reynolds 1984, 1997). The implications of slow mixing processes for phytoplankton competition are not well understood. However, field data and experiments clearly demonstrate that the intensity of mixing has a major impact on phytoplankton bloom development and on the species composition of phytoplankton blooms (Eppley et al. 1978; Reynolds et al. 1983; Viner and Kemp 1983; Steinberg and Zimmermann 1988; Jones and Gowen 1990; Cloern 1991; Visser et al. 1996; Berman and Shteinman 1998).

General ecological theory predicts that incomplete mixing should promote species coexistence (Levin 1974; Atkinson and Shorrocks 1981; Powell and Richerson 1985; Hsu and Waltman 1993; Tilman 1994). Coexistence in spatially explicit competition models is usually brought about by two different mechanisms. First, environmental heterogeneity may favor one species at one location, another species at another location, and so on, so that, integrated over the entire habitat, species can coexist. Second, even in an initially homogeneous environment, incomplete mixing combined with interspecific differences in growth and dispersal rates may lead to spatial segregation of the competing species. Spatial segregation of species reduces interspecific competition, thereby favoring coexistence (Ives and May 1985; Britton 1989; Hassell et al. 1994; Pacala and Levin 1997).

In aquatic environments, a prime factor that contributes to environmental heterogeneity is the light gradient. The light gradient, in turn, is at least partly created by light 
absorption by the phytoplankton species themselves. Moreover, mixing through a light gradient affects phytoplankton growth because mixing processes largely determine the light conditions experienced by the phytoplankton. Thus, it seems plausible that the vertical heterogeneity offered by the light gradient, especially when combined with incomplete mixing of the phytoplankton species, might promote species diversity (Weissing and Huisman 1994).

Earlier we developed a theory of interspecific competition for light that assumes complete mixing of phytoplankton species (Huisman and Weissing 1994, 1995; Weissing and Huisman 1994). The theory links the population dynamics of the species with changes in the light gradient caused by phytoplankton shading. The theory predicts that complete mixing should lead to competitive exclusion in a manner analogous to the $R^{*}$ principle of Armstrong and McGehee (1980) and Tilman (1982): the species with lowest "critical light intensity" should displace all other species. Recent laboratory experiments with wellmixed and light-limited continuous-culture systems confirm these predictions (Huisman 1999; Huisman et al. $1999 a)$.

We recently extended our approach to planktonic systems that are not well mixed, and discovered the existence of a "critical turbulence" (Huisman et al. 1999b). If vertical mixing rates exceed this critical turbulence, the phytoplankton species are relatively well mixed, and dense phytoplankton blooms can develop only if the mixed water column is shallow. However, if vertical mixing rates are less than the critical turbulence, blooms develop in a completely different manner. In this case, phytoplankton growth rates exceed the vertical mixing rates, the phytoplankton populations aggregate in the upper water column, and dense phytoplankton blooms can develop irrespective of water column depth (Huisman et al. 1999b). These predictions are consistent with empirical studies of phytoplankton blooms (Cloern 1991; Townsend et al. 1992; Eilertsen 1993). Hence, one might imagine that the competition theory described above (Huisman and Weissing 1994, 1995; Weissing and Huisman 1994) holds for mixing rates above the critical turbulence but does not hold for mixing rates below this level.

This article explores phytoplankton competition at different mixing rates. We develop a reaction-diffusion model with which we investigate competition for light during phytoplankton bloom development. More specifically, we want to address the following questions with the model: What kind of vertical distribution patterns of phytoplankton species will develop? Will incomplete mixing promote the species diversity of phytoplankton blooms? Will the species composition in well-mixed waters differ from the species composition in waters that are not well mixed?
Does the outcome of competition depend on the mixing rates? When is the critical light intensity a useful predictor for the outcome of competition for light? And how are bloom size and the species composition of phytoplankton blooms related to water column depth, vertical mixing rates, and other factors associated with the light gradient?

The model considers a eutrophic environment, where nutrients are in ample supply and light availability determines phytoplankton dynamics. The model analysis will demonstrate that mixing processes profoundly affect the species composition of phytoplankton blooms. However, incomplete mixing does not appear to promote species diversity in light-controlled environments. These findings explain the low species diversity observed in phytoplankton blooms of eutrophic waters and show why different phytoplankton species become dominant under different mixing regimes.

\section{Model}

We use a reaction-diffusion model (Okubo 1980; Murray 1989) to study spatial aspects of phytoplankton competition. The model is a spatial extension of earlier competition models (Huisman and Weissing 1994; Weissing and Huisman 1994; Huisman et al. 1999a) and a multispecies extension of a turbulent diffusion model that we analyzed recently (Huisman et al. 1999b). The model assumes that the population dynamics of the phytoplankton species are governed by local growth and local transport of phytoplankton. The growth rates of the phytoplankton species are driven by light availability. Light availability varies with depth, and the species compete with one another via shading. Local transport of the phytoplankton species is driven by turbulent diffusion. Turbulent diffusion is the random movement, in this case of phytoplankton, that is caused by many superimposed eddies moving in a very complicated way (Okubo 1980). These eddies can be induced by wind action, waves, cooling and related density changes of the water, and so on. To keep our analysis as simple as possible, the transport processes are restricted to turbulent diffusion. Further complications arising from sinking, buoyancy regulation, and algal motility are not considered here.

\section{Population Dynamics}

We consider a water column with a cross section of one unit area and with $n$ phytoplankton species. The phytoplankton species are indicated by different subscripts, like $i$ and $j$. Let $s$ denote the depth within the water column, where $s$ runs from 0 (top) to $z$ (bottom). And let $\omega_{1}(s, t)$ denote the population density (numbers per unit volume) of a phytoplankton species $i$ at depth $s$ and time $t$. The 
changes in the phytoplankton population densities can be described by the following set of partial differential equations:

$$
\begin{aligned}
\frac{\partial \omega_{i}}{\partial t}(s, t) & =\text { net growth }+ \text { net transport } \\
& =g_{i}(I(s, t)) \omega_{i}(s, t)-\frac{\partial J_{i}}{\partial s}(s, t), \\
i & =1, \ldots, n,
\end{aligned}
$$

where $g_{i}(I(s, t))$ is the net specific growth rate of phytoplankton species $i$ as a function of light intensity $I(s, t)$, and $J_{i}(s, t)$ is the net flux of phytoplankton species $i$. The change of flux with depth, $\partial J_{i} / \partial s$, gives the net change of the phytoplankton population density caused by local transport processes.

The net specific growth rate can be decomposed in a production term and a loss term:

$$
g_{i}(I(s, t))=p_{i}(I(s, t))-\ell_{i}, \quad i=1, \ldots, n .
$$

We assume that the specific production rate of a species $i, p_{i}(I(s, t))$, is an increasing and possibly saturating function of light intensity. Furthermore, there is no production without light; that is, $p_{i}(0)=0$. Phytoplankton losses are described by the specific phytoplankton loss rate, $\boldsymbol{\ell}_{i}$, which incorporates all sources of phytoplankton loss. The compensation point is defined as the light intensity, $I_{c, i}$, at which the net specific growth rate equals 0 .

We assume that phytoplankton transport is governed by turbulent diffusion. That is, the net flux of a phytoplankton species $i$ at depth $s$ is proportional to its local population density gradient:

$$
J_{i}(s, t)=-D_{i}(s) \frac{\partial \omega_{i}}{\partial s}(s, t), \quad i=1, \ldots, n,
$$

where the constant of proportionality, $D_{i}(s)$, is known as the turbulent diffusion coefficient (also known as the vertical eddy diffusivity), and the minus sign indicates that net diffusion fluxes are from high to low population densities. Note that our formulation allows the turbulent diffusion coefficients to vary with depth. In case of windinduced mixing, for example, the highest turbulent mixing rates are generally found near the top of the water column, and the turbulent motion dissipates with increasing depth (Mann and Lazier 1996; Reynolds 1997).

We assume that the water column is closed, with no phytoplankton cells entering or leaving the column at the top or the bottom. This gives the boundary conditions:

$$
\frac{\partial \omega_{i}}{\partial s}(0, t)=\frac{\partial \omega_{i}}{\partial s}(z, t)=0, \quad i=1, \ldots, n
$$

We also want to keep track of the population size per unit surface area of each species $i, W_{i}$, which is given by

$$
W_{i}=\int_{0}^{z} \omega_{i}(s, t) d s, \quad i=1, \ldots, n .
$$

Combining equations (1)-(5), the population size per unit surface area of a species $i$ changes with time according to

$$
\begin{aligned}
\frac{d W_{i}}{d t} & =\int_{0}^{z} \frac{\partial \omega_{i}}{\partial t}(s, t) d s \\
& =\int_{0}^{z} g_{i}(I(s, t)) \omega_{i}(s, t) d s \quad i=1, \ldots, n,
\end{aligned}
$$

where the flux terms cancel out because the boundaries are closed.

\section{Light Gradient}

The light intensity at each depth is described by LambertBeer's law (Kirk 1994). This law states that the amount of light absorbed at depth $s$ is proportional to the light intensity at depth $s$ :

$$
\frac{\partial I}{\partial s}(s, t)=-\mathbf{K}(s, t) I(s, t) .
$$

The constant of proportionality, $\mathrm{K}(s, t)$, consists of all components that absorb light, including the water itself and the phytoplankton species:

$$
\mathrm{K}(s, t)=K_{b g}+\sum_{j=1}^{n} k_{j} \omega_{j}(s, t),
$$

where $K_{b g}$ is the background turbidity that summarizes light absorption by all nonphytoplankton components, and $k_{j}$ is the specific light attenuation coefficient of phytoplankton species $j$.

Substituting equation (8) into equation (7) and integrating over depth gives the light intensity at depth $s$ and time $t$ : 
Table 1: Species' parameters, chosen to reflect three strategies in light-limited phytoplankton: super species, sun species, and shade species

\begin{tabular}{lcccl}
\hline Parameter & $\begin{array}{c}\text { Super species } \\
(\text { species 1) }\end{array}$ & $\begin{array}{c}\text { Sun species } \\
(\text { species 2) }\end{array}$ & $\begin{array}{c}\text { Shade species } \\
\text { (species 3) }\end{array}$ & \multicolumn{1}{c}{ Units } \\
\hline$p_{\max , i}$ & .050 & .040 & .030 & $\mathrm{~h}^{-1}$ \\
$\alpha_{i}$ & .0050 & .00133 & .003 & $\mathrm{~h}^{-1}\left(\mu \text { mol photons } \mathrm{m}^{-2} \mathrm{~s}^{-1}\right)^{-1}$ \\
$\ell_{i}$ & .02 & .02 & .02 & $\mathrm{~h}^{-1}$ \\
$k_{i}$ & .40 & .15 & .15 & $\mathrm{~cm}^{2}(\text { million cells })^{-1}$ \\
\hline
\end{tabular}

Note: The specific production rates are modeled using a simple Monod equation, $p_{i}(I)=p_{\max , i} \times$ $I /\left(\left[p_{\max , i} / \alpha_{i}\right]+I\right)$, where $p_{\max , i}$ is the maximum specific production rate and $\alpha_{i}$ is the slope of the $p_{i}(I)$-curve at $I=0$. All parameter values are within the ranges measured for freshwater phytoplankton species in the culture collection of the Laboratory for Microbiology, University of Amsterdam, The Netherlands (De Nobel et al. 1998; Huisman 1999; Huisman et al. 1999a; J. Huisman, unpublished data).

$$
I(s, t)=I_{\text {in }} \exp \left(-\left\{\int_{0}^{s}\left[\sum_{j=1}^{n} k_{j} \omega_{j}(\sigma, t)+K_{b g}\right] d \sigma\right\}\right) .
$$

In other words, the light intensity at any particular depth depends on the incident light intensity, $I_{\text {in }}$, and on the total light attenuation by the phytoplankton and the background turbidity above that depth. Note that the light gradient is dynamic in time. A change in any of the population densities of the phytoplankton species causes a concomitant change in the light gradient (eq. [9]). This, in turn, feeds back on the growth rates of the species (eq. [1]). Thus, the species interact with one another by changing the gradient of light intensities over depth.

\section{Simulations}

The model predictions were analyzed using a combination of analytical derivations and numerical simulations. Simulations of the model were based on an explicit forwardtime centered-space finite difference scheme (Noye 1984). We used a fine spatial discretization of at least 200 grid cells. Time steps were adjusted to meet the stability criterion $D(\Delta t) /(\Delta z)^{2}<1 / 2$, where $D$ is the largest turbulent diffusion coefficient in the model, $\Delta t$ is the time step, and $\Delta z$ is the depth of a single grid cell. To check the accuracy of our findings, we repeated several model simulations using another scheme, the Crank-Nicolson implicit finite difference method. The Crank-Nicolson scheme is more time consuming than the forward-time scheme but has smaller discretization errors (Noye 1984). Both schemes gave the same results. Whenever possible, we also checked our simulation results against analytical derivations. The simulations were always consistent with the analytical derivations.

\section{Coexistence and Competitive Exclusion}

We are interested in the question of under which circumstances species coexistence is possible. For systems of partial differential equations, it is usually hard to demonstrate coexistence on the basis of formal mathematical proofs. Totaro (1989), however, gave a formal proof that, at least for linear $p(I)$-functions, our reaction-diffusion system has a unique positive stationary solution that is globally stable whenever it exists. In other words, whenever a coexistence equilibrium exists, it is an attracting equilibrium independent of the initial conditions. Accordingly, we used two different simulation approaches to establish coexistence: short-term mutual invasion experiments, where a tiny amount of a species is inoculated in an equilibrium monoculture of another species to see whether it can invade; and long-term outcomes of competition. The results of the two simulation approaches were always consistent with each other.

\section{Illustration of a Model Run}

This section gives an example of a typical model run. We consider three species, which will be the leading characters throughout this article. The parameter values of the species are given in table 1, and their production and loss rates are plotted as a function of light intensity in figure 1 . Species 1 will be called a "super species." It is superior to the other species in that it has a higher production rate at all light intensities. Species 2 is a "sun species," at least compared with species 3 . It has a high maximum production rate at high light intensities, but its production rate is rather low at low light intensities. Species 3 is a "shade species," at least compared with species 2 . It has a relatively low maximum production rate, but maintains these production rates at low light intensities. For ease of illustration, we assume that all three species have the same specific loss rate.

Figure 2 shows the time course of competition between 


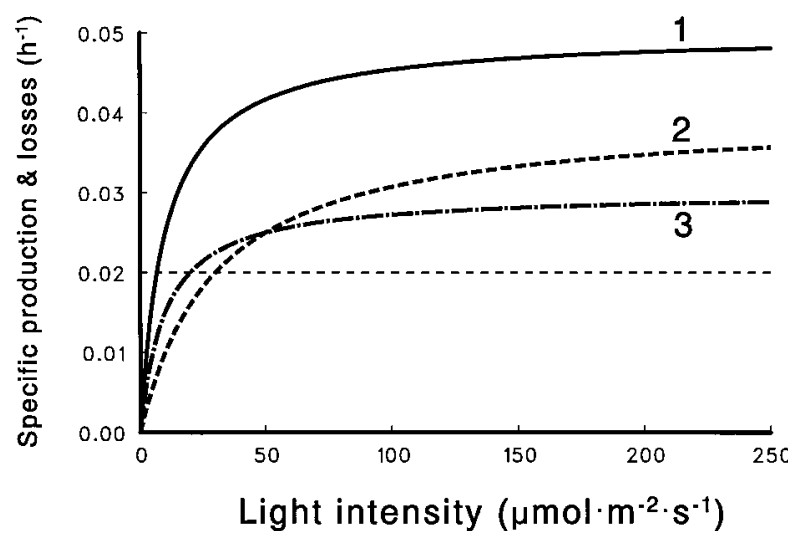

Figure 1: The specific production rates of three phytoplankton species, as functions of light intensity. Species 1 will be called a super species, species 2 a sun species, and species 3 a shade species. Horizontal dashed line indicates the specific loss rate of the species. For parameter values, see table 1 .

the three species for a particular set of environmental conditions. The figure assumes that mixing is relatively weak (i.e., $D_{i}$ is low), the same for all three species, and uniform over depth. At day 0, the populations are uniformly distributed over depth. All three species are initially rare, but the sun species and the shade species are given an initial advantage: both sun and shade species are 100 times more abundant than the super species (fig. $2 A$ ). During the first $10 \mathrm{~d}$, the population densities of all three species increase (fig. $2 B, C$ ). Because mixing is weak, population densities increase most rapidly at the top of the water column, where light conditions are most favorable and, hence, growth rates are highest. Owing to the increased population densities in the upper half of the water column, the light gradient becomes steeper (thin dashed line, fig. 2), and population densities at the bottom of the water column decline. This leads to further aggregation of the species in the upper part of the water column. The overall light conditions become less favorable for growth, and competitive effects by shading become evident. From approximately day 15 onward, the sun and shade species decline while the super species continues to increase (fig. $2 D, E$ ). After $25 \mathrm{~d}$, the super species has become dominant, and the sun and shade species are nearly completely excluded from the phytoplankton bloom (fig. $2 F$ ).

This example illustrates several interesting features that we observed in hundreds of simulations. First, at low mixing rates there is the obvious formation of a vertical pattern. Usually, vertical patterns developed within a few days. Second, competitive replacement may take several weeks, and sometimes even several months. This turned out to be especially true if inferior competitors were initially more abundant than superior competitors (as in fig. 2) or if the species were nearly equal competitors. This illustrates that initial abundances can have a great impact on the rate of successive replacement of phytoplankton species. However, in simulations where species were unequal competitors and the inferior competitors had no initial advantage, competitive replacement occurred much faster, usually within 1-2 wk. Third, in all simulations the dynamics led to a steady state. We did not observe any of the exciting nonequilibrium dynamics commonly observed in other reaction-diffusion models. Also, we found that the final outcome of competition was always independent of the initial conditions. We did not find any indication for the existence of multiple stable states. This is consistent with derivations of Ishii and Takagi (1982) and Totaro (1989), who gave a rigorous formal proof that, at least for linear $p(I)$-functions, our reaction-diffusion model has a unique positive stationary solution that is globally stable whenever it exists.

\section{Vertical Distribution Patterns}

In "Illustration of a Model Run," we considered a specific example. But, in general, what kind of vertical distribution patterns will develop when phytoplankton species compete for light? We address this question by deriving the stationary distributions of the phytoplankton population densities over depth. We recently made similar derivations for the single-species case with constant diffusion coefficients (Huisman et al. 1999b). Here we consider the multispecies case and allow the turbulent diffusion coefficients to vary with depth.

The stationary population density distributions of the species are obtained by solving $\partial \omega_{1} / \partial t=0$ for each species $i$. Hence, independent of whether a species grows alone or in a mixture with other species, combining equation (1) and equation (3) we obtain

$$
\frac{d}{d s}\left(D_{i}(s) \frac{d \omega_{i}^{*}}{d s}\right)=-g_{i}(I(s)) \omega_{i}^{*}(s),
$$

where the superscript asterisk indicates that the population density distribution is evaluated at equilibrium. Integrating both sides with respect to depth and using the boundary conditions to find that the constant of integration equals 0 , we obtain the slope of the stationary population density distribution of species $i$ :

$$
\frac{d \omega_{i}^{*}}{d s}=-\frac{1}{D_{i}(s)} \int_{0}^{s} g_{i}(I(\sigma)) \omega_{i}^{*}(\sigma) d \sigma .
$$


Population density $\left(10^{4}\right.$ cells $\left./ \mathrm{ml}\right)$

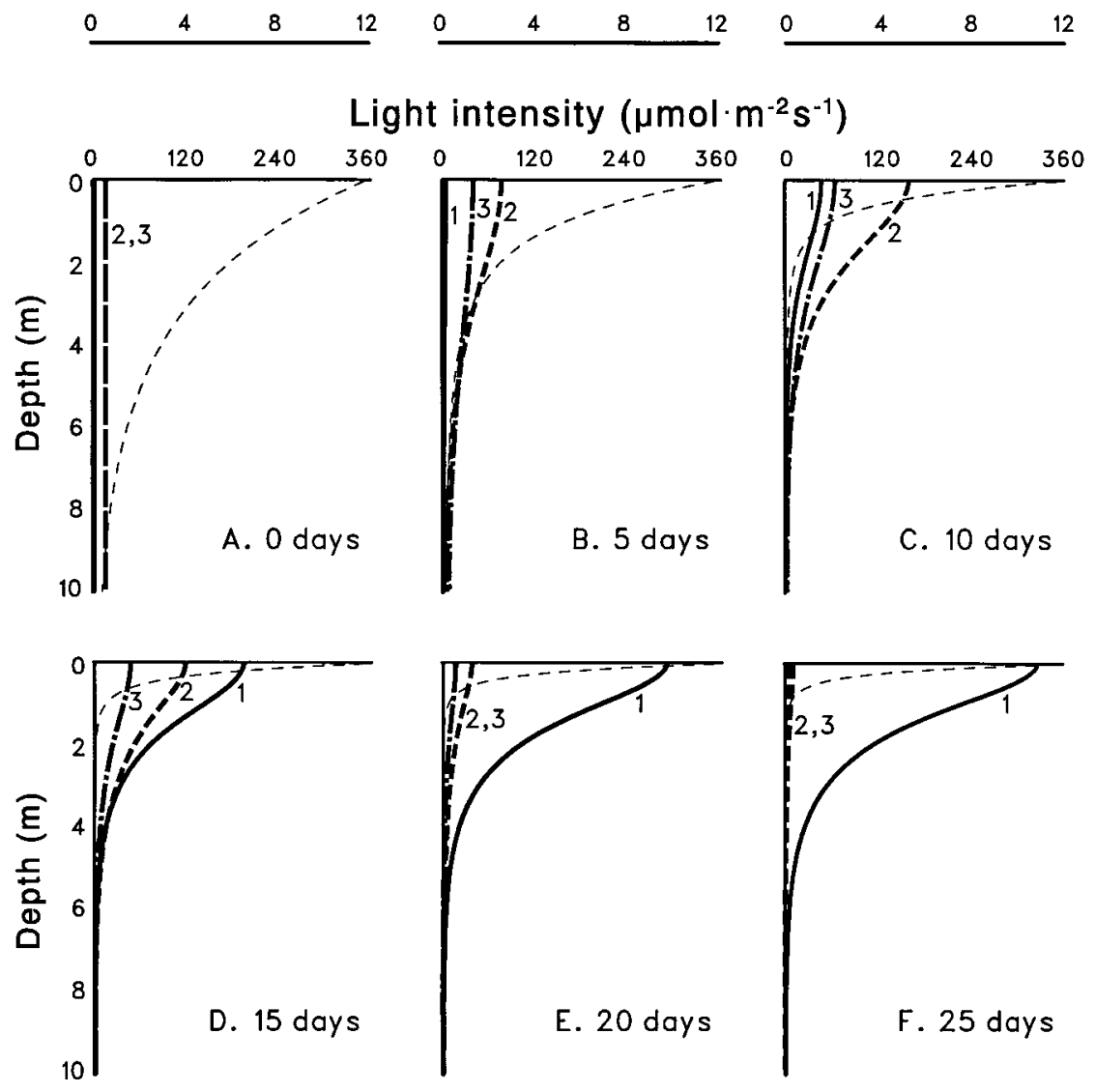

Figure 2: Time course of competition for light between the three phytoplankton species, assuming a relatively low turbulent diffusion coefficient. The three bold lines indicate the population densities. The thin dashed line indicates the light gradient. The graph shows the depth profiles at $A$, $t=0 \mathrm{~d} ; B, t=5 \mathrm{~d} ; C, t=10 \mathrm{~d} ; D, t=15 \mathrm{~d} ; E, t=20 \mathrm{~d} ; F, t=25 \mathrm{~d}$ of competition. For species' parameters, see table 1. Environmental parameters: $I_{\text {in }}=350 \mu \mathrm{mol}$ photons $\mathrm{m}^{-2} \mathrm{~s}^{-1} ; K_{b g}=0.2 \mathrm{~m}^{-1} ; z=10 \mathrm{~m} ; D_{1}=D_{2}=D_{3}=0.1 \mathrm{~cm}^{2} \mathrm{~s}^{-1}$, uniform over depth. Initial conditions: $\omega_{1}(s)=50$ cells $\mathrm{mL}^{-1} ; \omega_{2}(s)=5,000$ cells $\mathrm{mL}^{-1} ; \omega_{3}(s)=5,000$ cells $\mathrm{mL}^{-1}$, all uniform over depth.

Note that the integration boundaries in equation (11) range from 0 to $s$, whereas they ranged from 0 to $z$ in equation (6). Hence, using $d W_{i} / d t=0$ at equilibrium and the monotonic decrease of $g_{i}(I)$ with depth, it is easy to see that the integral term in equation (11) is positive as long as $0<s<z$ and $\omega_{i}^{*}(s)>0$. Thus, accommodating the minus sign, equation (11) shows that the stationary population density distributions should decrease monotonically with depth. That is,

$$
\frac{d \omega_{i}^{*}}{d s} \leq 0 \quad \text { for } 0<s<z
$$

with equality only if $\omega_{i}^{*}(s)=0$. This result is quite robust. The monotonic decrease of $g_{i}(I)$ with depth is a sufficient condition to derive equation (12), but it is not a necessary condition. The necessary condition is that the integral term in equation (11) remains positive. Hence, many nonmonotonic $g_{i}(I)$-functions also lead to the conclusion that the stationary population density distribution should decrease monotonically with depth. Only for very strong forms of nonmonotonicity in the $g_{i}(I)$-functions, such that net specific growth rates are negative in the upper part of the water column, will the conclusion of equation (12) be violated.

In the special case that $D_{i}$ is uniform over depth, equation (10) simplifies to 


$$
\frac{d^{2} \omega_{i}^{*}}{d s^{2}}=-\frac{1}{D_{i}} g_{i}(I(s)) \omega_{i}^{*}(s) .
$$

As a consequence, if $\omega_{i}^{*}(s)>0$,

$$
\begin{aligned}
& \frac{d^{2} \omega_{i}^{*}}{d s^{2}}<0 \text { for } I>I_{c, i}, \\
& \frac{d^{2} \omega_{i}^{*}}{d s^{2}}>0 \text { for } I<I_{c, i} .
\end{aligned}
$$

Hence, if the turbulent diffusion coefficient is uniform over depth, the stationary population density distribution is concave downward for light intensities above the compensation point, concave upward for light intensities below the compensation point, and has a point of inflection at the compensation point, $I_{c, i}$.

We are now able to summarize the shape of the stationary population density distributions of the phytoplankton species. For each species able to persist, its population density should decrease with increasing depth (eq. [12]), with zero slopes at the top and the bottom of the water column (eq. [4]). In the special case that the turbulent diffusion coefficient is constant over depth, the point of inflection is located at the depth at which the compensation point is reached (eq. [14]). The slope of the depth profile of a species depends on the magnitude of its depth-integrated phytoplankton growth rate relative to the magnitude of its turbulent diffusion coefficient. This is apparent from a comparison of the integrated growth term and the diffusion coefficient in equation (11). If the turbulent diffusion coefficient greatly exceeds the depthintegrated growth rate of a phytoplankton species, this species will be uniformly distributed over depth. In contrast, if the turbulent diffusion coefficient is low compared with its depth-integrated growth rate, the species will aggregate at the top of the water column (as in fig. $2 F$ ). The lower its turbulent diffusion coefficient, the more a species will tend to aggregate at the top of the water column.

Note that the above derivations were independent of whether a species grows alone or in a mixture with other species. That is, the stationary population density distributions of all phytoplankton species that can persist should decrease with depth (eq. [12]). Equilibrium distribution patterns as sketched in figure $3 A$ are thus conceivable, but patterns as sketched in figure $3 B$ are not. Hence, we have shown that there is a strong tendency against vertical segregation of phytoplankton species. The intuition behind this result is perhaps best expressed as follows: When species compete for light, they grow better next to their neighbors than in their shade.

These results indicate that turbulent diffusion does not provide much opportunity for species coexistence in light-
A. B.
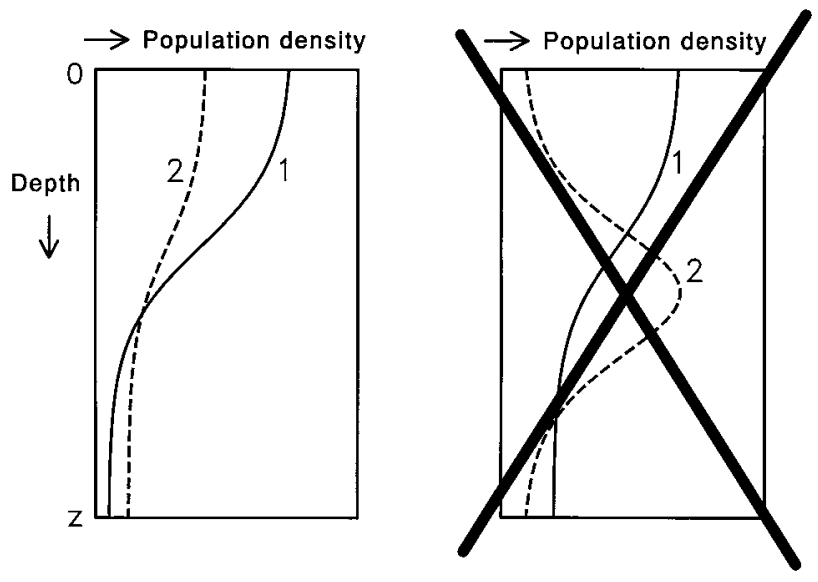

Figure 3: Competition for light combined with phytoplankton transport by turbulent diffusion may lead to depth profiles as in $A$ but not to depth profiles as in $B$.

controlled environments. Earlier we proved that without spatial differentiation, the species with lowest critical light intensity should competitively displace all other species (Weissing and Huisman 1994). In the context of turbulent diffusion, only some minor spatial differentiation is possible, and, hence, coexistence will still be difficult to achieve.

We emphasize that the above derivations assume that phytoplankton growth is driven by light availability and that phytoplankton transport is governed by turbulent diffusion. Other vertical patterns, perhaps with more opportunities for coexistence, may develop if other processes like nutrient depletion or algal motility are involved.

\section{Scaling Rules}

There is an intimate connection among the various parameters in the model. To illustrate this, we rescale the variables time, depth, and population densities by introducing the new variables

$$
\begin{aligned}
\hat{t} & =\beta t, \\
\hat{s} & =\gamma s, \\
\hat{\omega}_{i} & =\delta_{i} \omega_{i} \text { for all } i,
\end{aligned}
$$

where $\beta, \gamma$, and $\delta_{i}$ are some arbitrary constants. With these new variables we obtain a new dynamical system that has exactly the same form and, hence, exactly the same dynamics as the original system, but the model parameters have changed into 


$$
\begin{aligned}
\hat{g}_{i}(I) & =g_{i}(I) / \beta, \\
\hat{k}_{i} & =k_{i} /\left(\gamma \delta_{i}\right), \\
\hat{z} & =\gamma z, \\
\hat{K}_{b g} & =K_{b g} / \gamma, \\
\hat{D}_{i}(s) & =\left(\gamma^{2} / \beta\right) D_{i}(s) .
\end{aligned}
$$

These parameter transformations show how the parameters are linked. For example, the dynamics of the system remain qualitatively the same if we double both the diffusion coefficients and the net growth rates of the phytoplankton species (i.e., $\beta=1 / 2$ ). This only changes the timescale. If $\beta=1 / 2$, all processes will occur twice as fast.

Of particular interest is the special case where we choose $\beta=1, \gamma=c$, and $\delta_{i}=1 / c$, where $c$ is some arbitrary constant. This leaves the net growth rates $g_{i}(I)$ and the light attenuation coefficients $k_{i}$ of the species unaffected. The remaining parameter transformations

$$
\begin{gathered}
\hat{z}=c z, \\
\hat{K}_{b g}=K_{b g} / c, \\
\hat{D}_{i}(s)=c^{2} D_{i}(s),
\end{gathered}
$$

summarize the connection between water column depth, background turbidity, and turbulent diffusion. For example, suppose that we know the behavior of a certain planktonic system at a certain water column depth, but that water column depth is changed by a factor $c$. Then, according to equation (17), the dynamics remain exactly the same if the background turbidity is changed by a factor $1 / c$ and the turbulent diffusion coefficients by a factor $c^{2}$. Moreover, it is relatively easy to see that the population size per unit surface area then remains unaffected. However, according to equation (15), population densities will change by a factor $1 / c$. Thus, if the scaling rules of equation (17) are obeyed, water column depth and population densities can be changed drastically while keeping both the dynamics of the phytoplankton bloom and, therefore, the outcome of competition unaffected. This finding has some interesting implications for the design of plankton experiments, a point to which we return in the "Discussion."

\section{Complete Mixing}

This section is concerned with well-mixed systems and provides the background information against which the effects of incomplete mixing on competition for light can be compared. We will show that our previous competition model for well-mixed systems (Huisman and Weissing 1994, 1995; Weissing and Huisman 1994) is a limiting case of the reaction-diffusion model considered here. More precisely, if the turbulent diffusion coefficients are sufficiently high, the phytoplankton species will be approximately uniformly distributed over depth (see eq. [11]). Substituting uniform depth distributions $\omega_{i}(s, t)=\omega_{i}(t)$ in equations (5), (6), and (9) gives

$$
\begin{aligned}
\frac{d \omega_{i}}{d t} & =\frac{1}{z} \int_{0}^{z} g_{i}(I(s, t)) \omega_{i}(t) d s, \quad i=1, \ldots, n \\
I(s, t) & =I_{\text {in }} \exp \left\{-\left[\sum_{j=1}^{n} k_{j} \omega_{j}(t) s+K_{b g} s\right]\right\} .
\end{aligned}
$$

Accordingly, our competitive system simplifies to the competition models that we analyzed earlier. More precisely, if we define the light intensity at the bottom of the water column as $I_{\text {out }}=I(z)$, equations (18) and (19) can be rewritten as (Huisman and Weissing 1994; Weissing and Huisman 1994):

$$
\begin{aligned}
& \frac{d \omega_{i}}{d t}=\frac{1}{z} \frac{k_{i} \omega_{i}(t)}{\left[\sum_{j} k_{j} \omega_{j}(t)+K_{b g}\right]} \int_{I_{\text {out }}}^{I_{\text {in }}} \frac{g_{i}(I)}{k_{i} I} d I, \quad i=1, \ldots, n \\
& I_{\text {out }}=I_{\text {in }} \exp \left\{-\left[\sum_{j=1}^{n} k_{j} \omega_{j}(t) z+K_{b g} z\right]\right\}
\end{aligned}
$$

This model predicts that each species has its own critical light intensity. The critical light intensity is defined from the integral term in equation (20) as the value of $I_{\text {out }}$ at which $d \omega_{i} / d t=0$. It can be shown from equation (20) that a species will increase whenever the actual value of $I_{\text {out }}$ is above its critical light intensity (Huisman and Weissing 1994; Weissing and Huisman 1994). Conversely, a species will decrease if $I_{\text {out }}$ is below its critical light intensity. It follows that, in competition, the species with lowest critical light intensity should displace all other species because it is able to reduce $I_{\text {out }}$ below the critical light intensities of all other species (Huisman and Weissing 1994; Weissing and Huisman 1994). Experiments confirm these predictions (Huisman et al. 1999a).

The critical light intensity of a species is a complex function of its physiological characteristics and of environmental parameters. More specifically, according to equation (20) the critical light intensity is a decreasing function of incident light intensity (Huisman and Weissing 1994; Weissing and Huisman 1994; with experimental data 
in Huisman 1999). As an example, figure 4 gives the critical light intensities for the three species of figure 1 in relation to the incident light. This shows that the super species always has a lower critical light intensity than the other species. Thus, in well-mixed environments, the super species should always win. The curves of the sun species and shade species intersect. The shade species has a lower critical light intensity than the sun species for $I_{\text {in }}<520 \mu \mathrm{mol}$ photons $\mathrm{m}^{-2} \mathrm{~s}^{-1}$ but has a higher critical light intensity for $I_{\text {in }}>520 \mu \mathrm{mol}$ photons $\mathrm{m}^{-2} \mathrm{~s}^{-1}$ (fig. 4). Hence, in the absence of the super species, the shade species should displace the sun species for $I_{\text {in }}<520 \mu \mathrm{mol}$ photons $\mathrm{m}^{-2} \mathrm{~s}^{-1}$, and the sun species should displace the shade species for $I_{\text {in }}>520 \mu \mathrm{mol}$ photons $\mathrm{m}^{-2} \mathrm{~s}^{-1}$.

It also follows from equation (20) that the critical light intensity of a species is independent of background turbidity and water column depth. Furthermore, it follows from equation (21) that, in monoculture, the equilibrium population size per unit surface area that will be attained by a species can be calculated from its critical light intensity according to (Huisman 1999):

$$
W_{i}^{*}=\omega_{i}^{*} z=\frac{\ln \left(I_{\mathrm{in}}\right)-\ln \left(I_{\mathrm{out}, i}^{*}\right)}{k_{i}}-\frac{K_{b g}}{k_{i}} z,
$$

where $I_{\text {out }, i}^{*}$ is the critical light intensity of species $i$. Hence, the equilibrium population size per unit surface area is a linearly decreasing function of background turbidity and also a linearly decreasing function of water column depth. Note the important role of the background turbidity. If background turbidity were 0 , the equilibrium population size per unit surface area would be independent of water column depth. The validity of equation (22) is confirmed by earlier experiments (Huisman 1999).

In connection with the previous point, equation (22) predicts that there exists a critical depth of the water column. If a mixed water column is deeper than this critical depth, then the background turbidity alone imposes light conditions too dark to support any of the phytoplankton species. Thus, if $I_{\text {out }, 1}^{*}$ denotes the lowest critical light intensity among the competing species, the critical depth can be calculated from equation (22) as

$$
Z_{c r}=\frac{\ln \left(I_{\mathrm{in}}\right)-\ln \left(I_{\mathrm{out}, 1}^{*}\right)}{K_{b g}} \text {. }
$$

This is the multispecies generalization of the critical depth concept formulated earlier by Sverdrup (1953) and Platt et al. (1991), and extended by Huisman (1999).

It is important to realize that all derivations discussed in this section (eqq. [17]-[23]) hinge on the assumption of a well-mixed water column with uniform depth distributions of the phytoplankton species.

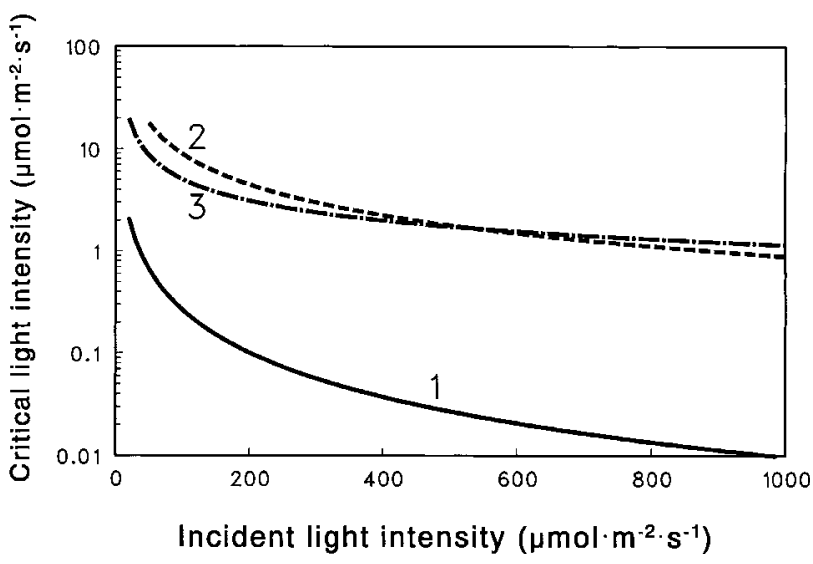

Figure 4: Critical light intensities of the three phytoplankton species in relation to incident light intensity. For species' parameters, see table 1.

\section{Incomplete Mixing and Differential Diffusion Rates}

Does the outcome of competition for light change if turbulent diffusion coefficients are low and, consequently, the competing species are not uniformly mixed? Unfortunately, rigorous mathematical proofs are usually difficult to obtain for systems that are not well mixed. Therefore, all illustrations that follow will be based on numerical simulations. Whenever possible, however, the simulation results will be interpreted in terms of the analytical derivations of the previous sections.

In many aquatic ecosystems, interspecific variation in the turbulent diffusion coefficients will probably be small, as even the smallest eddies that cause turbulent movement are generally larger than large phytoplankton species, so that all phytoplankton species are moved around by the same turbulence structure (Mann and Lazier 1996; Reynolds 1997). Nevertheless, some interspecific variation in the turbulent diffusion coefficients can be expected as phytoplankton species range from spherical cells of $<1 \mu \mathrm{m}$ in diameter to long intertwined filaments of $>1 \mathrm{~mm}$ length, a size difference that spans three orders of magnitude. It is hard to believe that such size differences do not create some interspecific differences in entrainment in the turbulent flows. In addition, a consideration of interspecific differences in the turbulent diffusion rates has heuristic value because these differences provide an additional axis for niche differentiation that may reveal opportunities for coexistence not available if all species would have the same turbulent mixing rates. Hence, this section asks what happens if competing species differ in their turbulent diffusion coefficients. For ease of illustration, we assume that the turbulent diffusion coefficients are uniform over depth.

Consider the sun species and shade species introduced earlier in figure 1. Figure 5 (top) gives the equilibrium 

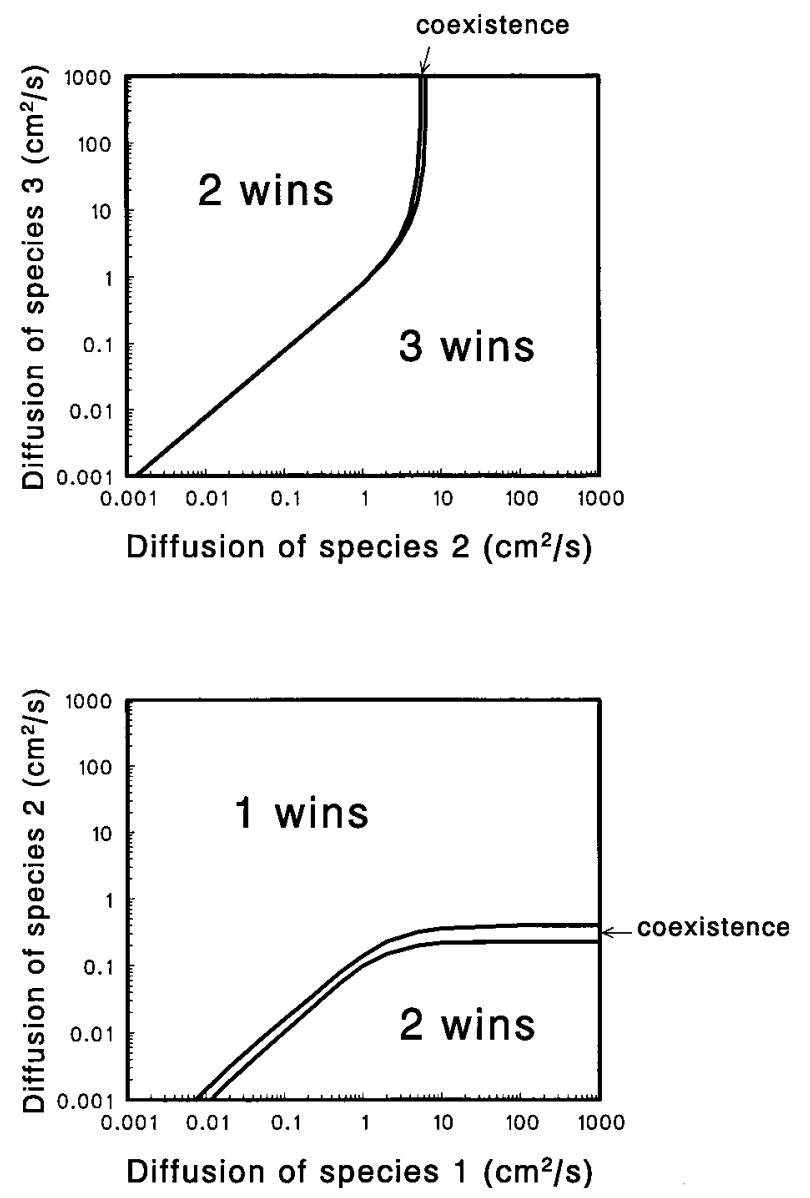

Figure 5: Outcome of competition, plotted for various combinations of the turbulent diffusion coefficients of the species. Top, Sun species (species 2) versus the shade species (species 3). Bottom, Super species (species 1) versus the sun species (species 2). For species parameters, see table 1 . Environmental parameters: $I_{\text {in }}=350 \mu \mathrm{mol}$ photons $\mathrm{m}^{-2} \mathrm{~s}^{-1} ; K_{b g}=0.2$ $\mathrm{m}^{-1} ; z=10 \mathrm{~m}$.

outcome of competition between these two species for a wide variety of combinations of their turbulent diffusion coefficients. The graph spans the entire spectrum from extremely slow mixing rates $\left(D_{i}=0.001 \mathrm{~cm}^{2} \mathrm{~s}^{-1}\right)$ to extremely fast mixing rates $\left(D_{i}=1,000 \mathrm{~cm}^{2} \mathrm{~s}^{-1}\right)$. We choose $I_{\text {in }}=350 \mu \mathrm{mol}$ photons $\mathrm{m}^{-2} \mathrm{~s}^{-1}$. At this incident light intensity, the shade species has a lower critical light intensity than the sun species (see fig. 4). Hence, if both species have high turbulent diffusion coefficients, they are both well mixed and the shade species wins (upper right corner of fig. 5, top). This outcome is modified, however, if only one of the species is well mixed and the other species has a low diffusion coefficient. In this case, the well-mixed species will be homogeneously distributed over depth, whereas the species with a low diffusion coefficient will aggregate at the top of the water column (see eq. [11]).
Obviously, a species that aggregates at the top of the water column has an enormous competitive advantage, as it shades other species but receives hardly any shading itself. Thus, if only the sun species is well mixed and the shade species is not, then the shade species aggregates at the top of the water column and the shade species wins (lower right corner of fig. 5, top). Conversely, if the shade species is well mixed but the sun species is not, then the sun species aggregates at the top of the water column and the sun species wins (upper left corner of fig. 5, top). Figure 5 , top, also illustrates that there is a steep transition between dominance by the sun species and dominance by the shade species. Only a very narrow range of turbulent diffusion coefficients allows both species to coexist.

Figure 5, bottom, gives another example, in which the super species and the sun species compete for light. Remember that the super species grows faster than the sun species at all light intensities (fig. 1). Hence, if both species are well mixed, the super species excludes the sun species (upper right in fig. 5, bottom). Also, if both species are not well mixed and the super species has an equal or lower turbulent diffusion coefficient than the sun species, the super species has the competitive advantage and wins (upper left of fig. 5 , bottom). However, if the super species is well mixed and the sun species has a very low diffusion coefficient, then the sun species will aggregate at the top of the water column and thus obtains a better position in the light gradient than the super species. Consequently, because of its better position, the sun species replaces the super species (lower right corner in fig. 5, bottom). There is only a narrow range of turbulent diffusion coefficients for which the two species coexist.

In summary, this section has shown that species with low turbulent diffusion coefficients have a competitive advantage, as they can escape from mixing and thereby obtain a better position in the light gradient. The critical light intensity is a good predictor for the outcome of competition for light only as long as all species are well mixed. It is not an adequate predictor for the outcome of competition for light if at least one of the species is not well mixed and obtains a better position in the light gradient. Opportunities for equilibrium coexistence of phytoplankton species in light-limited environments seem very limited, even if we allow for interspecific variation in turbulent diffusion rates.

\section{Incomplete Mixing in Different Environments}

This section illustrates how, according to the model, population sizes and species composition of phytoplankton blooms are related to different mixing regimes and other environmental conditions.

We assume in this section that the turbulent diffusion 
coefficients are the same for all species and uniform over depth. According to our simulations, if all species have the same turbulent diffusion coefficient and the $g_{i}(I)$ curves of the competing species do not intersect, then the species with the highest $g_{i}(I)$-curve always displaces all other species, irrespective of the turbulent diffusion coefficient, incident light intensity, background turbidity, or water column depth. Thus, considering the three species in figure 1, the super species should always win. Because this is not a very interesting scenario to investigate, we remove the super species from our species pool and restrict our attention to competition between the sun species and the shade species.

\section{Incomplete Mixing and Incident Light Intensity}

Population Size. Figure 6 shows the equilibrium population size per unit surface area as a function of incident light intensity (fig. $6 A, B$ ) and turbulent diffusion coefficient (fig. 6C, D). At very low incident light intensities, the light input is not sufficient to sustain a phytoplankton population (fig. 6A, B). Once incident light intensity is high enough to support a phytoplankton population, population size increases with incident light intensity, both at low mixing rates (fig. 6A) and at high mixing rates (fig. 6B).

The equilibrium population size per unit surface area decreases with increasing turbulent diffusion, both at a low and at a high incident light intensity (fig. $6 C, D$ ). This occurs because phytoplankton experience less shading from background turbidity when aggregated at the top of the water column (low turbulent diffusion) than when mixed throughout the water column (high turbulent diffusion). Once the phytoplankton are homogeneously mixed (at approximately $D>5 \mathrm{~cm}^{2} \mathrm{~s}^{-1}$ in fig. $6 C, D$ ), a further increase of the turbulent diffusion coefficient no longer affects population size.

Competition. Figure 7 shows the outcome of competition for light between the sun and shade species for different parameter combinations of incident light intensity and turbulent diffusion coefficient. Most strikingly, the figure shows that there are only two kinds of mixing regimes that appear to be relevant for the outcome of phytoplankton competition. One regime corresponds to well-mixed systems $\left(D>40 \mathrm{~cm}^{2} \mathrm{~s}^{-1}\right)$, and the other regime corresponds to systems that are not well mixed $\left(D<0.4 \mathrm{~cm}^{2}\right.$ $\left.\mathrm{s}^{-1}\right)$. There is a transition zone in between $(0.4<D<40$ $\left.\mathrm{cm}^{2} \mathrm{~s}^{-1}\right)$. In the well-mixed systems $\left(D>40 \mathrm{~cm}^{2} \mathrm{~s}^{-1}\right)$, the outcome of competition is not affected by changes in the turbulent diffusion coefficient. Here, the shade species wins the competition for $I_{\text {in }}<520 \mu \mathrm{mol}$ photons $\mathrm{m}^{-2} \mathrm{~s}^{-1}$, whereas the sun species wins the competition for $I_{\text {in }}>$
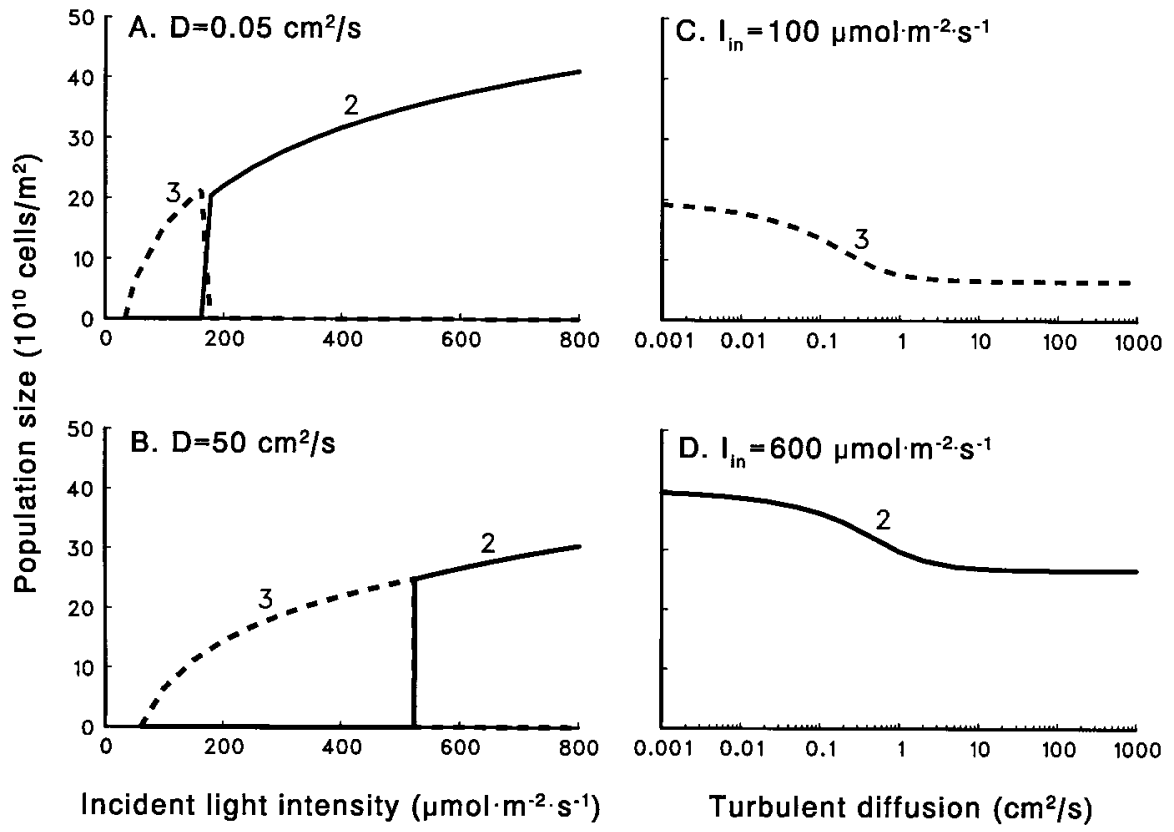

Figure 6: $A, B$, Equilibrium population size per unit surface area as a function of incident light intensity at $A$, low turbulent diffusion coefficient, and $B$, high turbulent diffusion coefficient. $C, D$, Equilibrium population size per unit surface area as a function of the turbulent diffusion coefficient at $C$, low incident light intensity, and $D$, high incident light intensity. Solid line, sun species (species 2); dashed line, shade species (species 3). For species' parameters, see table 1. Environmental parameters: $K_{b g}=0.2 \mathrm{~m}^{-1} ; z=10 \mathrm{~m}$. 


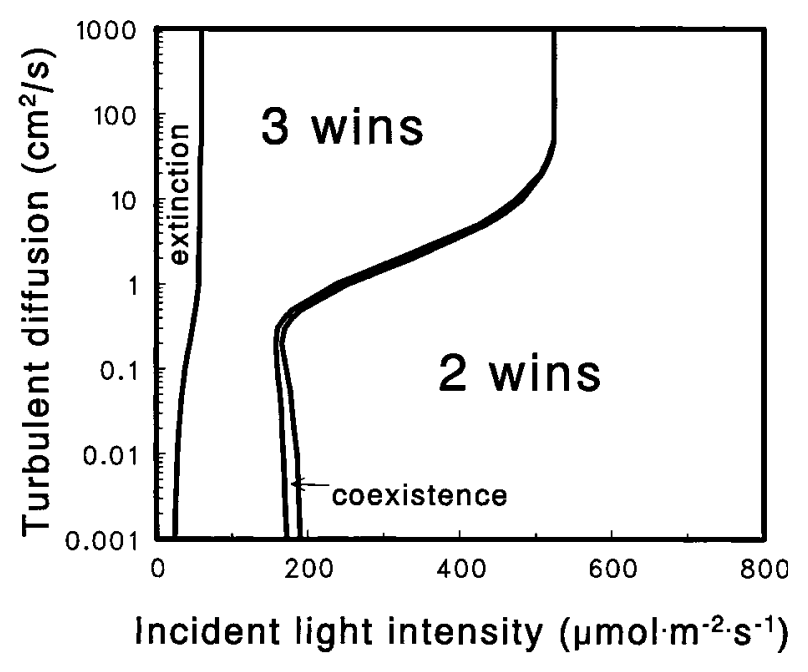

Figure 7: The outcome of competition between the sun species (species 2) and the shade species (species 3), plotted for various combinations of incident light intensity and turbulent diffusion coefficient. The graph assumes that the turbulent diffusion coefficient is the same for both species. For species' parameters, see table 1. Environmental parameters: $K_{b g}=0.2 \mathrm{~m}^{-1} ; z=10 \mathrm{~m}$.

$520 \mu \mathrm{mol}$ photons $\mathrm{m}^{-2} \mathrm{~s}^{-1}$. This outcome is compatible with the critical-light-intensity concept developed for competition in well-mixed systems, as the shade species has a lower critical light intensity than the sun species for $I_{\text {in }}<520 \mu \mathrm{mol}$ photons $\mathrm{m}^{-2} \mathrm{~s}^{-1}$, whereas the sun species has a lower critical light intensity than the shade species for $I_{\text {in }}>520 \mu \mathrm{mol}$ photons $\mathrm{m}^{-2} \mathrm{~s}^{-1}$ (see fig. 4). In systems that are not well mixed $\left(D<0.4 \mathrm{~cm}^{2} \mathrm{~s}^{-1}\right)$, the outcome of competition is also hardly affected by changes in the turbulent diffusion coefficient (fig. 7). Here, the sun species wins the competition for $I_{\text {in }}>185 \mu \mathrm{mol}$ photons $\mathrm{m}^{-2} \mathrm{~s}^{-1}$, whereas the shade species wins the competition for $I_{\text {in }}<$ $170 \mu \mathrm{mol}$ photons $\mathrm{m}^{-2} \mathrm{~s}^{-1}$, and there is a very narrow zone where both species coexist $\left(170<I_{\text {in }}<185 \mu \mathrm{mol}\right.$ photons $\mathrm{m}^{-2} \mathrm{~s}^{-1}$ ). The critical light intensity is not a good predictor for the outcome of competition for light in this region of parameter space, as the transition between dominance of species 2 and dominance of species 3 clearly is at another value of $I_{\text {in }}$ than that predicted by the critical light intensities of the two species.

Note that the sun species stays dominant at lower incident light intensities under incomplete mixing than in well-mixed systems (fig. 7). Our intuitive explanation is that under incomplete mixing, the phytoplankton species tend to grow in the upper part of the water column, where they face higher light intensities (figs. 2, 3A). This should benefit the sun species more than the shade species.

\section{Incomplete Mixing and Background Turbidity}

Population Size. Equilibrium population size per unit surface area decreases with increasing background turbidity, both at low mixing rates (fig. $8 A$ ) and at high mixing rates (fig. $8 B$ ). When background turbidity becomes too high, there is not sufficient light available to support a phytoplankton population, and the population goes extinct. Note the difference in slope between figure $8 A$ and figure $8 B$. The linear relationship in figure $8 B$, at high mixing rates, corresponds exactly to the prediction of equation (22). We have no explanation for the linearity of the relationship at low mixing rates (fig. $8 A$ ).

The turbulent diffusion coefficient hardly has any effect on the equilibrium population size per unit surface area when background turbidity is low (fig. 8C). Conversely, at high background turbidity the turbulent diffusion coefficient has a profound impact on the population size per unit surface area (fig. $8 D$ ). Here a phytoplankton population can be maintained only if low turbulent diffusion allows the phytoplankton to aggregate at the top of the water column and, hence, escape shading by background turbidity. Thus, background turbidity affects the relation between phytoplankton population size and turbulent mixing rates.

Competition. Figure 9 shows the outcome of competition in relation to background turbidity and the turbulent diffusion coefficient. The graph was made assuming an incident light intensity of $I_{\mathrm{in}}=350 \mu \mathrm{mol}$ photons $\mathrm{m}^{-2} \mathrm{~s}^{-1}$. Hence, it follows from results obtained earlier that the shade species should win in well-mixed systems, whereas the sun species should win in systems that are not well mixed (see fig. 7 at $I_{\text {in }}=350 \mu \mathrm{mol}$ photons $\mathrm{m}^{-2} \mathrm{~s}^{-1}$ ).

At high mixing rates $\left(D>5 \mathrm{~cm}^{2} \mathrm{~s}^{-1}\right.$ in fig. 9) the boundary line between "species 3 wins" and "extinction" coincides with the background turbidity at which water column depth equals the critical depth (in accordance with eq. [23]). At low mixing rates $\left(D<0.5 \mathrm{~cm}^{2} \mathrm{~s}^{-1}\right.$ in fig. 9) phytoplankton growth is still possible at higher background turbidities because the phytoplankton is aggregated in the upper part of the water column. Here the boundary line between "species 2 wins" and "extinction" follows the equation $D \propto 1 /\left(K_{b g}\right)^{2}$. This is consistent with our earlier derivation (Huisman et al. 1999b) that the critical turbulence for phytoplankton bloom development is inversely proportional to the square of background turbidity.

Figure 9 shows that the background turbidity has little effect on the outcome of competition for light. (Even though background turbidity does have an enormous effect on the population size per unit surface area; see fig. 8.) That is, independent of background turbidity, the sun species wins for $D<1 \mathrm{~cm}^{2} \mathrm{~s}^{-1}$, whereas the shade species 

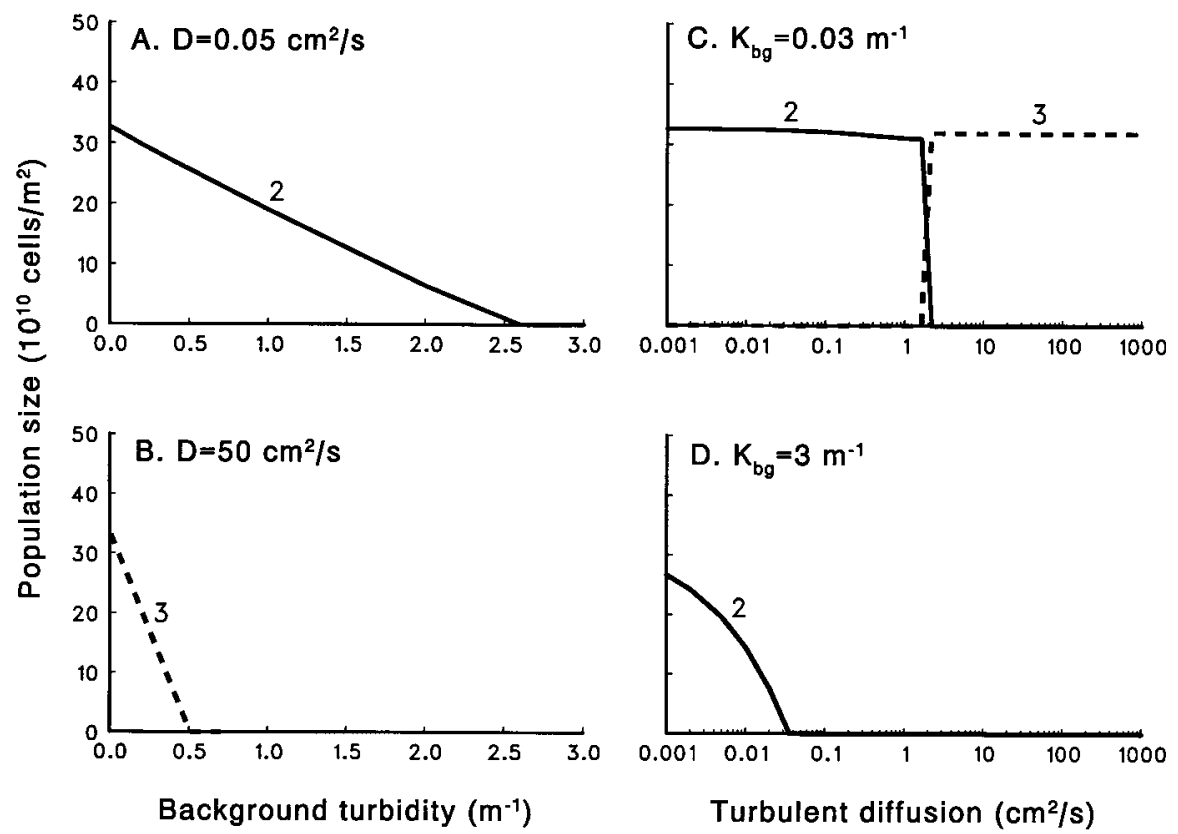

Figure 8: $A, B$, Equilibrium population size per unit surface area as a function of background turbidity at $A$, low turbulent diffusion coefficient, and $B$, high turbulent diffusion coefficient. $C, D$, Equilibrium population size per unit surface area as a function of the turbulent diffusion coefficient at $C$, low background turbidity, and $D$, high background turbidity. Solid line, sun species (species 2); dashed line, shade species (species 3 ). For species' parameters, see table 1 . Environmental parameters: $I_{\text {in }}=350 \mu$ mol photons $\mathrm{m}^{-2} \mathrm{~s}^{-1} ; z=10 \mathrm{~m}$.

wins for $D>3 \mathrm{~cm}^{2} \mathrm{~s}^{-1}$. There is a tendency for the region of coexistence to enlarge when background turbidity becomes low, but because the coexistence region is very small this effect seems almost negligible.

\section{Incomplete Mixing and Water Column Depth}

Population Size. At low mixing rates the phytoplankton aggregate in the upper part of the water column. Hence, phytoplankton dynamics become isolated from processes further downward. As a consequence, the equilibrium population size per unit surface area is independent of water column depth when mixing rates are low (fig. 10A). In contrast, when mixing rates are high phytoplankton do not remain at the top but face shading from the background turbidity when taken through the deeper parts of the water column. Hence, at high mixing rates the population size per unit surface area decreases with increasing water column depth and the population size becomes zero if water column depth exceeds a critical depth (fig. 10B). The linear relation in figure $10 \mathrm{~B}$ corresponds exactly to the prediction of equation (22), and the point at which population size becomes zero is the critical depth predicted by equation (23).

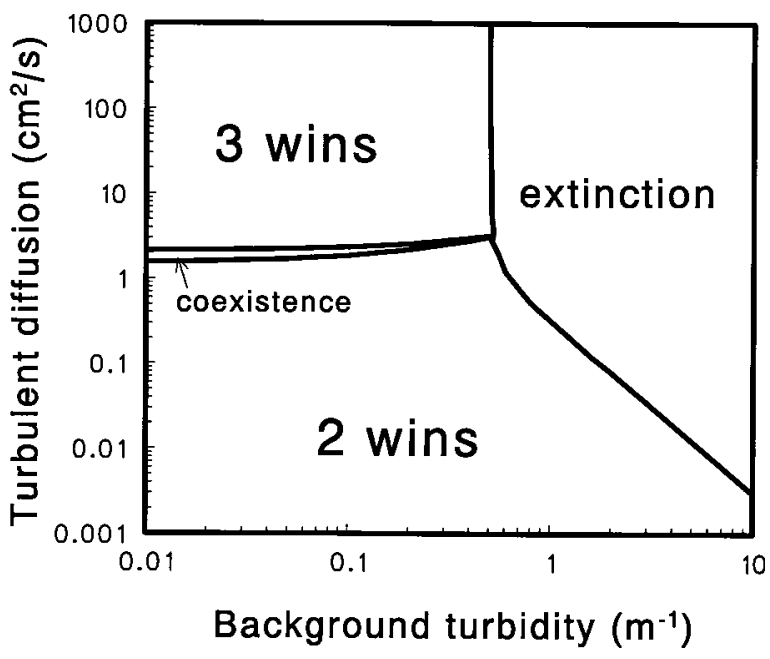

Figure 9: The outcome of competition between the sun species (species 2 ) and the shade species (species 3), plotted for various combinations of background turbidity and turbulent diffusion coefficient. The graph assumes that the turbulent diffusion coefficient is the same for both species. For species' parameters, see table 1. Environmental parameters: $I_{\text {in }}=$ $350 \mu \mathrm{mol}$ photons $\mathrm{m}^{-2} \mathrm{~s}^{-1} ; z=10 \mathrm{~m}$. 

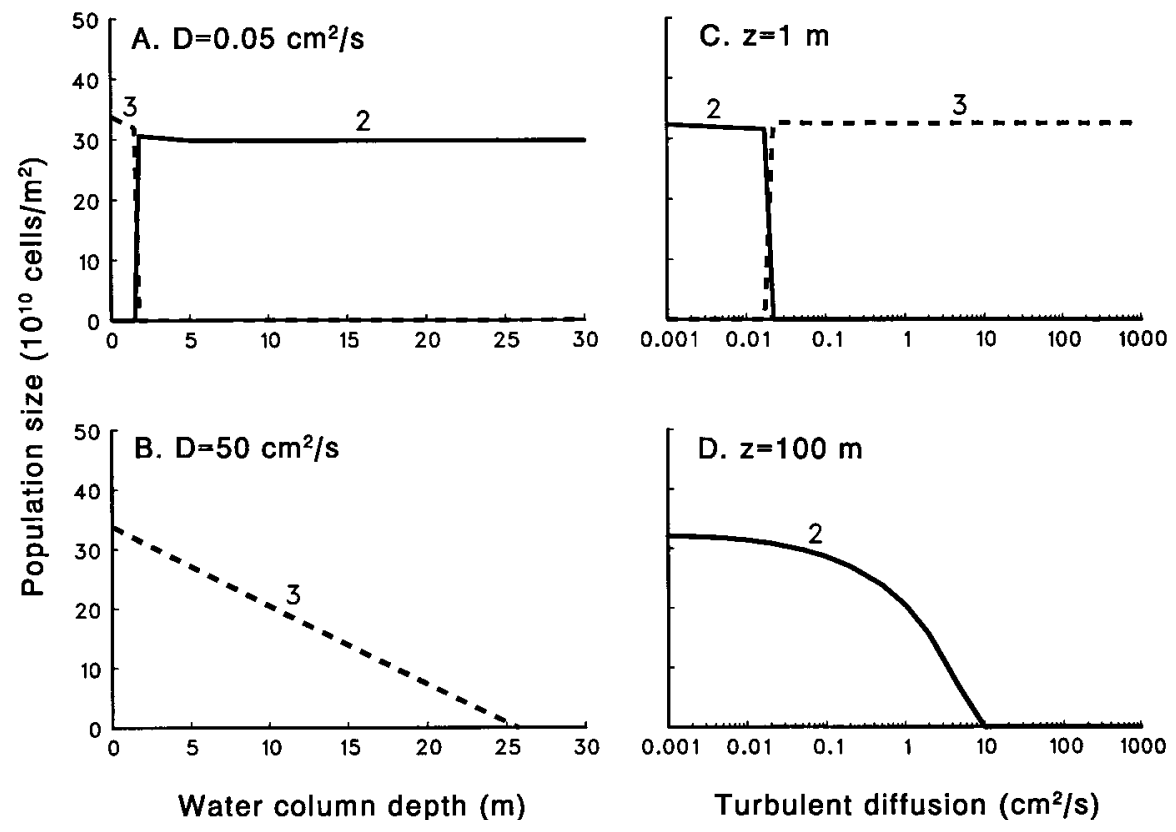

Figure 10: $A, B$, Equilibrium population size per unit surface area as a function of water column depth at $A$, low turbulent diffusion coefficient, and $B$, high turbulent diffusion coefficient. $C, D$, Equilibrium population size per unit surface area as a function of the turbulent diffusion coefficient in $C$, shallow water column, and $D$, deep water column. Solid line, sun species (species 2); dashed line, shade species (species 3). For species' parameters, see table 1. Environmental parameters: $I_{\mathrm{in}}=350 \mu \mathrm{mol}$ photons $\mathrm{m}^{-2} \mathrm{~s}^{-1} ; K_{b g}=0.2 \mathrm{~m}^{-1}$.

In very shallow systems, shading by the background turbidity is negligible. Hence, the equilibrium population size per unit surface area is independent of the turbulent mixing rates in such waters (fig. 10C). In contrast, in deep

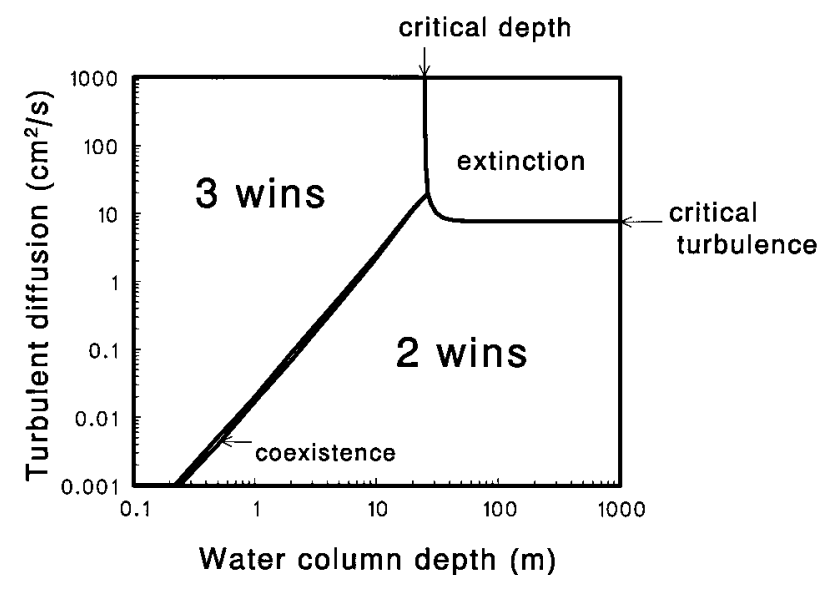

Figure 11: Outcome of competition between the sun species (species 2) and the shade species (species 3), plotted for various combinations of water column depth and turbulent diffusion coefficient. The graph assumes that the turbulent diffusion coefficient is the same for both species. For species' parameters, see table 1. Environmental parameters: $I_{\text {in }}=$ $350 \mu \mathrm{mol}$ photons $\mathrm{m}^{-2} \mathrm{~s}^{-1} ; K_{b g}=0.2 \mathrm{~m}^{-1}$. waters, phytoplankton receive less light when mixed to greater depths, because of shading by background turbidity. Thus, in deep waters, population size decreases with increasing turbulent diffusion coefficient. Population size becomes zero as soon as the turbulent diffusion coefficient exceeds a critical turbulence (fig. 10D).

Competition. The outcome of competition for light in relation to water column depth and the turbulent diffusion coefficient is shown in figure 11. As before, the graph assumes an incident light intensity of $I_{\text {in }}=350 \mu \mathrm{mol}$ photons $\mathrm{m}^{-2} \mathrm{~s}^{-1}$, so that the shade species wins in well-mixed systems and the sun species in systems that are not well mixed (see fig. 7).

In line with the results in figure 10, figure 11 illustrates that phytoplankton growth is possible only if water column depth is below a critical depth or if the turbulent diffusion coefficient is below a critical turbulence. Note that the critical depth is independent of the turbulent diffusion coefficient and that the critical turbulence is independent of water column depth. This illustrates that there are two independent and fundamentally different mechanisms for phytoplankton bloom development: one mechanism based on the critical depth (sensu Sverdrup 1953), and the other mechanism based on the critical turbulent mixing rate within the water column (sensu Huisman et al. 1999b). 
Table 2: The most important model predictions

\begin{tabular}{|c|c|}
\hline Prediction & Summary \\
\hline 1. & $\begin{array}{l}\text { Maximum bloom size per unit surface area depends on the key parameters of incident light intensity, } \\
\text { background turbidity, water column depth, and turbulent mixing rates. }\end{array}$ \\
\hline 2. & $\begin{array}{l}\text { Large blooms per unit surface area can develop if the incident light intensity is high and shading by } \\
\text { background turbidity is avoided. }\end{array}$ \\
\hline 3. & $\begin{array}{l}\text { Shading by background turbidity is avoided if background turbidity itself is low, or if the water col- } \\
\text { umn is shallow, or if turbulent mixing rates are low and phytoplankton aggregate at the top of the } \\
\text { water column. }\end{array}$ \\
\hline 4. & The species composition of phytoplankton blooms is not related to bloom size per unit surface area. \\
\hline 5. & $\begin{array}{l}\text { The species composition is profoundly affected by the turbulent mixing rates, and the species compo- } \\
\text { sition in well-mixed waters generally differs from the species composition in waters that are not } \\
\text { well mixed. }\end{array}$ \\
\hline 6. & $\begin{array}{l}\text { The critical light intensity is a good predictor for the outcome of competition for light between phy- } \\
\text { toplankton species in well-mixed waters. }\end{array}$ \\
\hline 7. & $\begin{array}{l}\text { The critical light intensity is not a good predictor for the outcome of competition for light in waters } \\
\text { that are not well mixed, because vertical positions of the species in the light gradient become } \\
\text { prevalent. }\end{array}$ \\
\hline 8. & $\begin{array}{l}\text { Opportunities for vertical segregation of phytoplankton species are limited in light-controlled } \\
\text { environments. }\end{array}$ \\
\hline 9. & Species diversity of phytoplankton blooms is low. \\
\hline 10. & $\begin{array}{l}\text { The dynamics and outcome of competition remain unaffected across different scales if the scaling } \\
\text { rules of equation (17) are obeyed. }\end{array}$ \\
\hline
\end{tabular}

Figure 11 shows that the turbulent diffusion coefficient at which competitive dominance shifts from the sun species to the shade species increases with water column depth. More precisely, the slope of the boundary lines between "species 2 wins" and "species 3 wins" obeys a simple power-law relation that can be derived from the scaling rules of equation (17) and our previous results in figure 9. Figure 9 showed that the outcome of competition was nearly independent of background turbidity. Consequently, assuming that effects of background turbidity on competition can be neglected, the scaling rules of equation (17) state that a change in water column depth by a factor $c$ can be compensated by changing the turbulent diffusion coefficient by a factor $c^{2}$. Hence, the boundary lines can be approximated by the simple power-law equation $D \propto$ $z^{2}$. This gives a slope of 2 when $D$ and $z$ are plotted on a $\log$-log scale, in agreement with the slope shown in figure 11. The slight curvature in the slope of the boundary lines is caused by minor effects of background turbidity on competition. More loosely, one might summarize the shift in species dominance in figure 11 simply by saying that the shade species wins under complete mixing but loses under incomplete mixing and that a deeper water column requires a higher turbulent diffusion rate to become well mixed.

\section{Discussion}

This article demonstrates, by means of a reaction-diffusion model, that mixing processes and competition for light should have a profound impact on the dynamics and species composition of phytoplankton blooms in eutrophic waters. The mechanism is illustrated in figure 2. If phytoplankton populations increase, they absorb more light and the light gradient becomes steeper. The steeper light gradient, in turn, feeds back on further population growth and competition. Mixing rates have a major effect on this process because they affect the vertical distribution of the phytoplankton populations and, thereby, the steepness of the light gradient, the vertical arrangement that determines how the species shade each other, and the light conditions experienced by the phytoplankton species.

Table 2 gives a summary of the most important model predictions. We will now go through this list, motivate our predictions, and compare the predictions with the available data.

\section{Bloom Size per Unit Surface Area (Predictions 1-3)}

The equilibrium population size per unit surface area predicted by the model can best be interpreted as the maximum number of phytoplankton cells per unit surface area that a phytoplankton bloom can attain. The population size may remain smaller, for example, because of nutrient depletion or grazing. But the population can never grow larger because the light energy available is not sufficient to support a larger phytoplankton population. The model shows that the maximum population size varies from 0 to 
very dense phytoplankton populations, depending on the key factors of incident light intensity, background turbidity, water column depth, and turbulent mixing rates (figs. $6,8,10)$. The background turbidity, in particular, plays an important role because it intercepts part of the light energy that would otherwise have been available for phytoplankton growth. A large phytoplankton population can develop only if shading by background turbidity is avoided. Hence, a large phytoplankton population can develop in two ways. First, if the water column is very shallow or has a low background turbidity, so that light absorption by the background turbidity is negligible (figs. $8 C, 10 C$; left part of fig. $8 A, B$; left part of fig. 10B). Second, if the water column is deep but mixing rates are low, so that phytoplankton aggregate at the top of the water column and thereby escape shading by background turbidity (fig. 10A; left part of figs. $8 D, 10 D)$. If these conditions are not met, the phytoplankton face too much shading from the background turbidity and the model predicts that the maximum population size will remain small (right part of fig. $8 A, B, D$; right part of fig. $10 B, D)$.

Are these patterns consistent with data? Laboratory evidence for the relation between incident light intensity and population size (shown in fig. $6 A, B$ ) is given in Huisman (1999). Numerous field studies have also shown a positive relation between incident light intensity and phytoplankton population size (e.g., Hitchcock and Smayda 1977; Boucher et al. 1984; Bradford and Chang 1987; Gleitz et al. 1994). Evidence for the negative effects of background turbidity on phytoplankton population size (fig. 8A, B) comes from the field experiments of Cuker (1987), the comparative lake study of Millard and Sager (1994), and the whole-lake manipulations of Carpenter et al. (1998). We are not aware of any laboratory experiment or field study that has investigated the interactive effects of background turbidity and turbulent mixing on population size (illustrated in fig. $8 C, D$ ). Field evidence that phytoplankton blooms can develop independent of water column depth when turbulent mixing rates are low (fig. 10A) comes from Townsend et al. (1992) and Eilertsen (1993). Laboratory evidence that population size decreases linearly with water column depth in well-mixed systems (fig. 10B) is given in Huisman (1999). The prediction that high turbulent mixing rates do not reduce population size in very shallow lakes (fig. 10C) is supported by the study of Harding (1997). Field evidence that high turbulent mixing rates reduce the population size in optically deep waters (fig. 10D) comes from the studies of Bailey-Watts et al. (1987), Cloern (1991), Ragueneau et al. (1996), Yin et al. (1996), and Berman and Shteinman (1998). Hence, many laboratory experiments and field investigations have documented patterns of phytoplankton population size that are consistent with the model predictions.

\section{Species Composition of Phytoplankton Blooms (Predictions 4-7)}

The model predicts that the winner of competition for light depends on the mixing regime. For example, in wellmixed environments, the species with lowest critical light intensity is predicted to win. This prediction is confirmed by recent competition experiments (Huisman et al. 1999a). But at low mixing rates the species with lowest critical light intensity can be displaced by other phytoplankton species if these other species are able to obtain a better position in the light gradient (fig. 5). Moreover, the model does not predict a gradual change in species composition along a gradient of turbulent mixing rates. Instead, there appears to be a steep transition between the dominance regions of the species. In all simulations, this transition in species composition occurred when the system shifted from being well mixed to being not well mixed (figs. 7, 9, 11).

Many field studies support these predictions. For example, Balch (1981) found a striking correlation between the phytoplankton species composition in the Gulf of Maine and the monthly tidal cycle. Diatoms were most abundant during the major spring tide, when mixing is most intense. The species composition changed to dominance by dinoflagellates during the intervening minor spring and neap tides, which provide more stable water conditions. Jones and Gowen (1990) found a similar pattern for coastal regions of the British Isles; diatoms were favored in well-mixed water columns, whereas dinoflagellates dominated when the water was stratified. Moreover, as Jones and Gowen (1990, p. 557) put it, "the domain of co-dominance of diatoms and dinoflagellates was narrow ... with small changes in the irradiance or stratification regime resulting in a switch to diatom or dinoflagellate dominance." This matches our model results, where there is only a narrow transition zone between the dominance regions of the species, and codominance of species is rare (figs. 7, 9, 11).

In a shallow eutrophic lake in Denmark, Jacobsen and Simonsen (1993) observed a massive summer bloom of the cyanobacterium Aphanizomenon flos-aquae. At the end of July, during a period of high winds and heavy rainfall, the Aphanizomenon biomass collapsed from $140 \mathrm{~mm}^{3} \mathrm{~L}^{-1}$ in July to $6.2 \mathrm{~mm}^{3} \mathrm{~L}^{-1}$ in early August. The lake was still stratified, though, and Aphanizomenon continued to dominate, although at much lower biomass. In late August, new storms destroyed the stratification, and Aphanizomenon was replaced by cryptomonad species. Again, these results are consistent with our model findings. According to the model, if turbulent mixing rates increase but are insufficient to cause a transition to well-mixed systems, the same species may remain dominant (figs. 7, 9, 11). 
The model predicts major changes in species composition if there is a true transition from incomplete to complete mixing, as happened only in late August in Jacobsen and Simonsen's study (1993).

In Lake Nieuwe Meer, a hypertrophic lake in the Netherlands, nuisance blooms of the cyanobacterium Microcystis dominated the phytoplankton for many years (Visser et al. 1996). Using continuous-culture experiments, we observed that Microcystis is not the best competitor for light in well-mixed systems (Huisman et al. 1999a). However, when mixing rates are as low as in Lake Nieuwe Meer, gas vesicles give Microcystis sufficient buoyancy to accumulate at the top of the water column (Visser et al. 1996; see also Reynolds and Walsby 1975; Zohary and Breen 1989). Consequently, Microcystis obtains a better position in the light gradient than other species, and therefore it can intercept most of the incident light. A solution to break the dominance of Microcystis was found by artificial mixing of the lake. Artificial mixing prevented Microcystis blooms, and the phytoplankton shifted to a mixture of other species (Visser et al. 1996). In a sense, Microcystis behaved like species 2 in figure 5 (bottom). Species 2 is inferior to species 1 in all respects and does not stand a chance in well-mixed systems. Yet species 2 displaces species 1 at low mixing rates if species 2 is able to obtain a better position in the light gradient (fig. 5, bottom).

Numerous other studies provide additional evidence for the hypothesis that mixing processes are a critical determinant of the species composition of phytoplankton communities in eutrophic waters (Eppley et al. 1978; Reynolds et al. 1983; Viner and Kemp 1983; Bailey-Watts et al. 1987; Cowell et al. 1987; Steinberg and Zimmermann 1988; Reynolds and Bellinger 1992; Berman and Shteinman 1998; Sherman et al. 1998).

Are changes in species composition correlated with changes in total population size? Not necessarily. For instance, in fig. $8 C$, dominance shifts from species 2 at low mixing rates to species 3 at high mixing rates, but population size remains constant. Similar patterns are found in figure $10 \mathrm{~A}$ and figure $10 \mathrm{C}$. In other instances, the species composition remains the same but population size changes considerably (fig. $8 A, B, D$; fig. $10 B, D$ ). The explanation is that a process like competition is not related to the absolute biomass within a community but to the relative performance of species with respect to one another. That is, in figure $8 C$, mixing rates do not affect total population size because shading by background turbidity is negligible. But mixing rates do affect the outcome of competition because mixing rates affect the spatial positions of the species relative to one another. Thus, the model predicts that, in eutrophic environments, changes in species composition are often unrelated to changes in total phytoplankton biomass.

\section{Species Diversity of Phytoplankton Blooms \\ (Predictions 8-9)}

Ecological theory predicts that environmental heterogeneity and incomplete mixing promote species diversity and coexistence (Levin 1974; Ives and May 1985; Hassell et al. 1994; Tilman 1994; Pacala and Levin 1997). Indeed, in the present analysis we found that complete mixing leads to competitive exclusion, whereas incomplete mixing does create some opportunities for coexistence. However, the opportunities for coexistence in light-controlled environments seem very limited. We found coexistence for only a very narrow range of species parameters and environmental conditions (figs. 5, 7, 9, 11). We tried numerous other species combinations in our simulations (results not shown), but this did not change our findings. For instance, we considered pairs of species that were more similar than the sun and shade species of figure 1. In this case, the time required for competitive exclusion increased, but the width of the region in parameter space that allowed equilibrium coexistence remained the same or became smaller. Also, we considered pairs of species that were more dissimilar than the sun and shade species of figure 1. For most of these species combinations, the coexistence region was narrowed further or there was no coexistence at all. The coexistence region was enlarged, however, if the difference in nonlinearity between the $p(I)$ functions of the sun and shade species was emphasized (i.e., a linear $p(I)$ relation for species 2 and a strongly curved $p(I)$ relation for species 3 in fig. 1). But, also in this case, the coexistence region usually remained quite small. In total, for the hundreds of species combinations that we investigated, by far the great majority of parameter combinations led to competitive exclusion.

The model offers two explanations for the predominance of competitive exclusion. First, opportunities for vertical segregation of the phytoplankton species are limited in light-controlled environments because all species tend to aggregate at the top of the water column (figs. 2, 3). Second, competitive interactions are not at a purely local level (as in the models of Ives and May 1985; Hassell et al. 1994; Tilman 1994). Instead, there is a more global competitive interaction involved because light absorption at the top of the water column affects all individuals below. That is, there is little vertical escape from competition for light. Hence, we conclude that competition for light should lead to phytoplankton blooms dominated by a single or, at most, a few species that outcompete all others.

This view is supported by field observations. Eutrophication shifts phytoplankton competition from competition for nutrients to competition for light. The observation that eutrophication reduces phytoplankton species diversity is one of the best-documented patterns in aquatic 
ecology (Yount 1956; Williams 1964; Taslakian and Hardy 1976; Gelin and Ripl 1978; Friligos and Gotsis-Skretas 1987; Elber and Schanz 1989; Chellappa 1990; Schindler 1990; Barnese and Schelske 1994; Romo and Miracle 1995; Hough and Thompson 1996; Maasdam and Claassen 1998). Moreover, phytoplankton blooms in eutrophic environments that have been sufficiently stable for a sufficiently long time are frequently dominated by a single species that outcompeted all others. Nearly monospecific blooms in eutrophic waters have been found for cyanobacteria like Anabaenopsis (G.-Tóth and Padisák 1986), Aphanizomenon (Jacobsen and Simonsen 1993), Limnothrix (Olrik and Nauwerck 1993), Microcystis (Zohary 1985; Visser et al. 1996), and Planktothrix (Berger and Bij de Vaate 1983) and also for green algae (Holmgren 1984), diatoms (Sournia et al. 1987), dinoflagellates (Chang 1988), and "brown tide" algae (Sieburth et al. 1988; Buskey and Hyatt 1995). Switches between years dominated by one species and years dominated by another species have also been observed (Reynolds and Bellinger 1992). Thus, many algal blooms in eutrophic waters tend to be dominated by only one or a few species, a pattern that is consistent with the model predictions.

\section{Patterns that Disagree with the Theory (Contra Predictions 8-9)}

It would be unfair to discuss studies that support the model predictions without mentioning studies that contradict the theory. A particularly strong prediction of the model is that, for all species, population densities should decrease with depth (fig. 3). This prediction forms the basis for predictions 8 and 9 in table 2 . The prediction is incompatible, however, with, for instance, the presence of deep chlorophyll maxima in various marine systems (Anderson 1969; Cullen 1982; Mann and Lazier 1996), with metalimnetic maxima in several freshwater lakes (Klemer 1976; Gasol et al. 1992; Gervais 1997), and with the vertical distributions of motile phytoplankton species (Blasco 1978; Sommer and Gliwicz 1986; Olsson and Granéli 1991).

There are good reasons why these vertical distribution patterns deviate from the theory developed here. The theory in this article assumes that phytoplankton growth is driven by light availability and that phytoplankton transport is governed by turbulent diffusion. Deep chlorophyll maxima in marine environments usually develop when nutrient concentrations in the upper part of the water column have been depleted. As a consequence, phytoplankton is mostly confined to greater depths where more nutrients are available (Jamart et al. 1977; Mann and Lazier 1996). Hence, in this case, growth in the upper water column is not driven by light availability but by nutrient depletion. Deep chlorophyll maxima may also develop if grazing is strongly depth dependent. For example, Kononen et al. (1998) observed that grazing by ciliates in the Baltic Sea was mostly restricted to the layer above the thermocline, whereas phytoplankton inhabited both the layer above the thermocline and the thermocline itself. This led to a subsurface chlorophyll maximum at the thermocline. Metalimnetic maxima in freshwater lakes develop under stable stratified conditions and are typically dominated by cryptomonads, flagellated chrysophytes, or cyanobacteria like Planktothrix rubescens and Planktothrix mougeotii (Fee 1976; Klemer 1976; Gervais 1997). Cryptomonads and flagellated chrysophytes are motile phytoplankton species. Planktothrix rubescens and P. mougeotii are capable of regulating their buoyancy. Hence, the vertical positions of these species are not governed by turbulent diffusion, but they can actively seek their own favorite position within the water column (Walsby and Klemer 1974; Gervais 1997). Similarly, vertical distribution patterns of large motile phytoplankton species like the Volvocales and many dinoflagellate species are clearly not governed by turbulent diffusion. These species may perform diurnal vertical migrations that span vertical distances of 5-20 m (Eppley et al. 1968; Blasco 1978; Sommer and Gliwicz 1986).

In summary, deviations from the theory may certainly arise in more complex situations, when factors like nutrient depletion, depth-dependent grazing, or active motility of phytoplankton generate nonmonotonic relations between phytoplankton population densities and depth.

\section{Limitations and Perspectives (Prediction 10)}

To the best of our knowledge, the reaction-diffusion model analyzed here is the first competition model that explicitly links phytoplankton competition for light with physical mixing processes. The model has led to a large number of testable predictions (table 2). As we have argued, these predictions are qualitatively consistent with many existing laboratory experiments and field data. Therefore, the model may serve as a unifying framework to understand the dynamics and species composition of phytoplankton blooms in eutrophic waters.

However, the model assumptions are still limited in several respects. As indicated above, the model does not consider the buoyancy regulation or active motility of phytoplankton. The model also neglects photoinhibition and sinking. These aspects may change the vertical patterning of the species and, thereby, affect phytoplankton competition. Furthermore, we omitted factors like selective grazing, parasitic infections, and interactions between nutrient limitation and competition for light, even though these factors often have a major impact on the dynamics and 
species composition of phytoplankton communities (Sterner 1989; Bruning et al. 1992; Grover 1995; Huisman and Weissing 1995; Leibold et al. 1997). Also, regular disturbances in the mixing regime may have implications for phytoplankton competition (Padisák et al. 1993). We neglected all these additional complexities to restrict our attention to more fundamental aspects of incomplete mixing and competition for light. Integrating light competition with nutrient competition, grazing, algal motility, and many other facets will be an important next step, however. It is probable that many additional complexities can be incorporated by straightforward extensions of the reaction-diffusion model. Hence, the conceptual framework developed here provides several entries for further theoretical investigations that may contribute to a further integration of our understanding of planktonic communities.

Our findings also provide suggestions for experiments and fieldwork. While most model predictions are qualitatively consistent with the existing data, more detailed quantitative studies of nearly all predictions are still lacking. Quantitative tests of the theory will require measurement of the turbulent mixing rates and will benefit from experimental plankton systems that allow controlled study of phytoplankton competition at low mixing rates (see Sanford 1997 for some guidelines). Scaling rules may be particularly relevant because they detail how phytoplankton blooms observed in the field can be mimicked at laboratory scale. Scaling rules show how the same phytoplankton dynamics can be preserved across different scales. For instance, suppose that one wants to mimic a phytoplankton bloom found in a natural lake of $10 \mathrm{~m}$ deep, using an experimental system only $1 \mathrm{~m}$ deep. Then the light conditions experienced by the phytoplankton bloom in the lake can be simulated by adjusting the background turbidity and turbulent mixing rates in the experiment. Adjustment of the background turbidity ensures that the light gradient is comparable to the lake situation. Adjustment of the turbulent diffusion coefficient ensures that the mixing rate of phytoplankton through the light gradient is comparable to the lake situation. More precisely, according to equation (17), background turbidity should be 10 times higher and the turbulent diffusion coefficient should be 100 times lower in the experimental system in order to mimic the light conditions experienced in the lake. Most present-day laboratory experiments probably do not meet these stringent scaling requirements, but it will be a challenge to adopt the scaling rules in future experimentation as a tool to study competition in phytoplankton blooms under well-controlled and replicable conditions.

\section{Acknowledgments}

J. Huisman thanks J. Roughgarden for providing good facilities and a pleasant working environment to do this research. We are grateful to S. R. Connolly, M. A. Leibold, H. Pereira, J. Roughgarden, and the two anonymous referees for their helpful comments on the manuscript. The investigations of J. Huisman were supported by a TALENT grant from the Netherlands Organization for Scientific Research (NWO), and by a grant from the Earth and Life Sciences Foundation, which is subsidized by NWO. This is publication 2537 of the Center for Estuarine and Marine Ecology, Yerseke.

\section{Literature Cited}

Anderson, G. C. 1969. Subsurface chlorophyll maximum in the Northeast Pacific Ocean. Limnology and Oceanography 14:386-391.

Armstrong, R. A., and R. McGehee. 1980. Competitive exclusion. American Naturalist 115:151-170.

Atkinson, W. D., and B. Shorrocks. 1981. Competition on a divided and ephemeral resource: a simulation model. Journal of Animal Ecology 50:461-471.

Bailey-Watts, A. E., E. J. Wise, and A. Kirika. 1987. An experiment in phytoplankton ecology and applied fishery management: effects of artificial aeration on troublesome algal blooms in a small eutrophic loch. Aquaculture and Fisheries Management 18:259-276.

Balch, W. M. 1981. An apparent lunar tidal cycle of phytoplankton blooming and community succession in the Gulf of Maine, USA. Journal of Experimental Marine Biology and Ecology 55:65-78.

Barnese, L. E., and C. L. Schelske. 1994. Effects of nitrogen, phosphorus and carbon enrichment on planktonic and periphytic algae in a softwater, oligotrophic lake in Florida, USA. Hydrobiologia 277:159-170.

Berger, C., and A. Bij de Vaate. 1983. Limnological studies on the eutrophication of Lake Wolderwijd: a shallow hypertrophic Oscillatoria dominated lake in The Netherlands. Swiss Journal of Hydrology 45:458-479.

Berman, T., and B. Shteinman. 1998. Phytoplankton development and turbulent mixing in Lake Kinneret (1992-1996). Journal of Plankton Research 20:709-726.

Blasco, D. 1978. Observations on the diel migration of marine dinoflagellates off the Baja California coast. Marine Biology 46:41-47.

Boucher, P., D. W. Blinn, and D. B. Johnson. 1984. Phytoplankton ecology in an unusually stable environment (Montezuma Well, Arizona, USA). Hydrobiologia 119: 149-160.

Bradford, J. M., and F. H. Chang. 1987. Standing stocks and productivity of phytoplankton off Westland, New 
Zealand. New Zealand Journal of Marine and Freshwater Research 21:71-90.

Britton, N. F. 1989. Aggregation and the competitive exclusion principle. Journal of Theoretical Biology 136: 57-66.

Bruning, K., R. Lingeman, and J. Ringelberg. 1992. Estimating the impact of fungal parasites on phytoplankton populations. Limnology and Oceanography 37:252-260.

Buskey, E. J., and C. J. Hyatt. 1995. Effects of the Texas (USA) "brown tide" alga on planktonic grazers. Marine Ecology Progress Series 126:285-292.

Carpenter, S. R., J. J. Cole, J. F. Kitchell, and M. L. Pace. 1998. Impact of dissolved organic carbon, phosphorus, and grazing on phytoplankton biomass and production in experimental lakes. Limnology and Oceanography 43: 73-80.

Chang, F. H. 1988. Distribution, abundance, and size composition of phytoplankton off Westland, New Zealand, February 1982. New Zealand Journal of Marine and Freshwater Research 22:345-368.

Chellappa, N. T. 1990. Phytoplankton species composition, chlorophyll biomass, and primary production of the Jundias Reservoir (northeastern Brazil) before and after eutrophication. Acta Hydrobiologica 32:75-92.

Cloern, J. E. 1991. Tidal stirring and phytoplankton bloom dynamics in an estuary. Journal of Marine Research 49: 203-221.

Cowell, B. C., C. J. Dawes, W. E. Gardiner, and S. M. Scheda. 1987. The influence of whole lake aeration on the limnology of a hypereutrophic lake in central Florida (USA). Hydrobiologia 148:3-24.

Cuker, B. E. 1987. Field experiment on the influences of suspended clay and $\mathrm{P}$ on the plankton of a small lake. Limnology and Oceanography 32:840-847.

Cullen, J. J. 1982. The deep chlorophyll maximum: comparing vertical profiles of chlorophyll $a$. Canadian Journal of Fisheries and Aquatic Sciences 39:791-803.

De Nobel, W. T., H. C. P. Matthijs, E. Von Elert, and L. R. Mur. 1998. Comparison of the light-limited growth of the nitrogen-fixing cyanobacteria Anabaena and Aphanizomenon. New Phytologist 138:579-587.

Ducobu, H., J. Huisman, R. R. Jonker, and L. R. Mur. 1998. Competition between a prochlorophyte and a cyanobacterium under various phosphorus regimes: comparison with the Droop model. Journal of Phycology 34:467-476.

Eilertsen, H. C. 1993. Spring blooms and stratification. Nature (London) 363:24.

Elber, F., and F. Schanz. 1989. The causes of change in the diversity and stability of phytoplankton communities in small lakes. Freshwater Biology 21:237-252.

Eppley, R. W., O. Holm-Hansen, and J. D. Strickland. 1968.
Some observations on the vertical migrations of dinoflagellates. Journal of Phycology 4:333-340.

Eppley, R. W., P. Koeller, and G. T. Wallace, Jr. 1978. Stirring influences the phytoplankton species composition within enclosed columns of coastal sea water. Journal of Experimental Marine Biology and Ecology 32: 219-240.

Fee, E. J. 1976. The vertical and seasonal distribution of chlorophyll in lakes of the Experimental Lakes Area, northwestern Ontario: implications for primary production estimates. Limnology and Oceanography 21: 767-783.

Friligos, N., and O. Gotsis-Skretas. 1987. Relationships of phytoplankton with certain environmental factors in the South Euboikos Gulf (Greece). Marine Ecology 8:59-74.

Gasol, J. M., R. Guerrero, and C. Pedrós-Alió. 1992. Spatial and temporal dynamics of a metalimnetic Cryptomonas peak. Journal of Plankton Research 14:1565-1579.

Gelin, C., and W. Ripl. 1978. Nutrient decrease and response of various phytoplankton size fractions following the restoration of Lake Trummen, Sweden. Archiv für Hydrobiologie 81:339-367.

Gervais, F. 1997. Diel vertical migration of Cryptomonas and Chromatium in the deep chlorophyll maximum of a eutrophic lake. Journal of Plankton Research 19: 533-550.

Gleitz, M., U. V. Bathmann, and K. Lochte. 1994. Buildup and decline of summer phytoplankton biomass in the eastern Weddell Sea, Antarctica. Polar Biology 14: 413-422.

Grover, J. P. 1991. Resource competition in a variable environment: phytoplankton growing according to the variable-internal-stores model. American Naturalist 138:811-835.

1995. Competition, herbivory, and enrichment: nutrient-based models for edible and inedible plants. American Naturalist 145:746-774.

G.-Tóth, L., and J. Padisák. 1986. Meteorological factors affecting the bloom of Anabaenopsis raciborskii Wolosz. (Cyanophyta: Hormogonales) in the shallow Lake Balaton, Hungary. Journal of Plankton Research 8:353-363.

Harding, W. R. 1997. Phytoplankton primary production in a shallow, well-mixed, hypertrophic South African lake. Hydrobiologia 344:87-102.

Hassell, M. P., H. N. Comins, and R. M. May. 1994. Species coexistence and self-organizing spatial dynamics. Nature (London) 370:290-292.

Hitchcock, G. L., and T. J. Smayda. 1977. The importance of light in the initiation of the 1972-1973 winter-spring diatom bloom in Narragansett Bay. Limnology and Oceanography 22:126-131.

Holmgren, S. K. 1984. Experimental fertilization in the Kuokkel area, northern Sweden: phytoplankton biomass 
and algal composition in natural and fertilized subarctic lakes. Internationale Revue der Gesamten Hydrobiologie 69:781-817.

Hough, R. A., and R. L. Thompson, Jr. 1996. The influence of a dissolved inorganic nitrogen gradient on phytoplankton community dynamics in a chain of lakes. Hydrobiologia 319:225-235.

Hsu, S. B., and P. Waltman. 1993. On a system of reactiondiffusion equations arising from competition in an unstirred chemostat. Society for Industrial and Applied Mathematics Journal on Applied Mathematics 53: 1026-1044.

Huisman, J. 1999. Population dynamics of light-limited phytoplankton: microcosm experiments. Ecology 80: 202-210.

Huisman, J., and F. J. Weissing. 1994. Light-limited growth and competition for light in well-mixed aquatic environments: an elementary model. Ecology 75:507-520.

- 1995. Competition for nutrients and light in a mixed water column: a theoretical analysis. American Naturalist 146:536-564.

Huisman, J., R. R. Jonker, C. Zonneveld, and F. J. Weissing. 1999a. Competition for light between phytoplankton species: experimental tests of mechanistic theory. Ecology 80:211-222.

Huisman, J., P. van Oostveen, and F. J. Weissing. 19996. Critical depth and critical turbulence: two different mechanisms for the development of phytoplankton blooms. Limnology and Oceanography (in press).

Hutchinson, G. E. 1974. De rebus planktonicis. Limnology and Oceanography 19:360-361.

Ishii, H., and I. Takagi. 1982. Global stability of stationary solutions to a nonlinear diffusion equation in phytoplankton dynamics. Journal of Mathematical Biology 16: $1-24$.

Ives, A. R., and R. M. May. 1985. Competition within and between species in a patchy environment: relations between microscopic and macroscopic models. Journal of Theoretical Biology 115:65-92.

Jacobsen, B. A., and P. Simonsen. 1993. Disturbance events affecting phytoplankton biomass, composition, and species diversity in a shallow, eutrophic, temperate lake. Hydrobiologia 249:9-14.

Jamart, B. M., D. F. Winter, K. Banse, G. C. Anderson, and R. K. Lam. 1977. A theoretical study of phytoplankton growth and nutrient distribution in the Pacific Ocean off the Northwest U.S. coast. Deep-Sea Research 24:753-773.

Jones, K. J., and R. J. Gowen. 1990. Influence of stratification and irradiance regime on summer phytoplankton composition in coastal and shelf seas of the British Isles (UK). Estuarine Coastal and Shelf Science 30:557-568.

Kirk, J. T. O. 1994. Light and photosynthesis in aquatic ecosystems. 2d ed. Cambridge University Press, Cambridge.

Klemer, A. R. 1976. The vertical distribution of Oscillatoria agardhii var. isothrix. Archiv für Hydrobiologie 78: 343-362.

Kononen, K., S. Hallfors, M. Kokkonen, H. Kuosa, J. Laanemets, J. Pavelson, and R. Autio. 1998. Development of a subsurface chlorophyll maximum at the entrance to the Gulf of Finland, Baltic Sea. Limnology and Oceanography 43:1089-1106.

Leibold, M. A., J. M. Chase, J. B. Shurin, and A. L. Downing. 1997. Species turnover and the regulation of trophic structure. Annual Review of Ecology and Systematics 28:467-494.

Levin, S. A. 1974. Dispersion and population interactions. American Naturalist 108:207-228.

Maasdam, R., and T. H. L. Claassen. 1998. Trends in water quality and algal growth in shallow Frisian lakes, The Netherlands. Water Science and Technology 37:177-184.

Mann, K. H., and J. R. N. Lazier. 1996. Dynamics of marine ecosystems: biological-physical interactions in the oceans. 2d ed. Blackwell, Oxford.

Millard, E. S., and P. E. Sager. 1994. Comparison of phosphorus, light climate, and photosynthesis between two culturally eutrophied bays: Green Bay, Lake Michigan, and the Bay of Quinte, Lake Ontario. Canadian Journal of Fisheries and Aquatic Sciences 51:2579-2590.

Murray, J. D. 1989. Mathematical biology. Springer, Berlin.

Noye, J. 1984. Finite difference techniques for partial differential equations. Pages 95-354 in J. Noye, ed. Computational techniques for differential equations. Elsevier, The Netherlands.

Okubo, A. 1980. Diffusion and ecological problems: mathematical models. Springer, Berlin.

Olrik, K., and A. Nauwerck. 1993. Stress and disturbance in the phytoplankton community of a shallow, hypertrophic lake. Hydrobiologia 249:15-24.

Olsson, P., and E. Granéli. 1991. Observations on diurnal vertical migration and phased cell division for three coexisting marine dinoflagellates. Journal of Plankton Research 13:1313-1324.

Pacala, S. W., and S. A. Levin. 1997. Biologically generated spatial pattern and the coexistence of competing species. Pages 204-232 in D. Tilman and P. Kareiva, eds. Spatial ecology: the role of space in population dynamics and interspecific interactions. Princeton University Press, Princeton, N.J.

Padisák, J., C. S. Reynolds, and U. Sommer, eds. 1993. Intermediate disturbance hypothesis in phytoplankton ecology. Hydrobiologia 249:1-199.

Platt, T., D. F. Bird, and S. Sathyendranath. 1991. Critical depth and marine primary production. Proceedings of 
the Royal Society of London B, Biological Sciences 246: 205-217.

Powell, T., and P. J. Richerson. 1985. Temporal variation, spatial heterogeneity, and competition for resources in plankton systems: a theoretical model. American Naturalist 125:431-464.

Ragueneau, O., B. Quéguiner, and P. Trégeur. 1996. Contrast in biological responses to tidally-induced vertical mixing for two macrotidal ecosystems of western Europe. Estuarine Coastal and Shelf Science 42:645-665.

Reynolds, C. S. 1984. The ecology of freshwater phytoplankton. Cambridge University Press, Cambridge.

- 1997. Vegetation processes in the pelagic: a model for ecosystem theory. Ecology Institute, Oldendorf.

Reynolds, C. S., and E. G. Bellinger. 1992. Patterns of abundance and dominance of the phytoplankton of Rostherne Mere, England: evidence from an 18-year data set. Aquatic Sciences 54:10-36.

Reynolds, C. S., and A. E. Walsby. 1975. Water blooms. Biological Reviews of the Cambridge Philosophical Society 50:437-481.

Reynolds, C. S., S. W. Wiseman, B. M. Godfrey, and C. Butterwick. 1983. Some effects of artificial mixing on the dynamics of phytoplankton populations in large limnetic exclosures. Journal of Plankton Research 5: 203-234.

Romo, S., and R. Miracle. 1995. Diversity of the phytoplankton assemblages of a polymictic hypertrophic lake. Archiv für Hydrobiologie 132:363-384.

Rothhaupt, K. O. 1996. Laboratory experiments with a mixotrophic chrysophyte and obligately phagotrophic and phototrophic competitors. Ecology 77:716-724.

Sanford, L. P. 1997. Turbulent mixing in experimental ecosystem studies. Marine Ecology Progress Series 161: 265-293.

Schindler, D. W. 1990. Experimental perturbations of whole lakes as tests of hypotheses concerning ecosystem structure and function. Oikos 57:25-41.

Sherman, B. S., I. T. Webster, G. J. Jones, and R. L. Oliver. 1998. Transitions between Aulacoseira and Anabaena dominance in a turbid river weir pool. Limnology and Oceanography 43:1902-1915.

Sieburth, J. McN., P. W. Johnson, and P. E. Hargraves. 1988. Ultrastructure and ecology of Aureococcus anophagefferens gen. et sp. nov. (Chrysophyceae): the dominant picoplankter during a bloom in Narragansett Bay, Rhode Island, Summer 1985. Journal of Phycology 24: 416-425.

Sommer, U. 1985. Comparison between steady state and non-steady state competition: experiments with natural phytoplankton. Limnology and Oceanography 30: 335-346.

Sommer, U., and Z. M. Gliwicz. 1986. Long range vertical migration of Volvox in tropical Lake Cahora Bassa (Mozambique). Limnology and Oceanography 31:650-653.

Sournia, A., J. L. Birrien, J. L. Douville, B. Klein, and M. Viollier. 1987. A daily study of the diatom spring bloom at Roscoff (France) in 1985. I. The spring bloom within the annual cycle. Estuarine Coastal and Shelf Science 25:355-368.

Steinberg, C., and G. Zimmermann. 1988. Intermittent destratification: a therapy measure against cyanobacteria in lakes. Environmental Technology Letters 9:337-350.

Sterner, R. W. 1989. The role of grazers in phytoplankton succession. Pages 107-170 in U. Sommer, ed. Plankton ecology: succession in plankton communities. Springer, Berlin.

Sverdrup, H. U. 1953. On conditions for the vernal blooming of phytoplankton. Journal du Conseil Conseil Permanent International pour l'Exploration de la Mer 18: 287-295.

Taslakian, M. J., and J. T. Hardy. 1976. Sewage nutrient enrichment and phytoplankton ecology along the central coast of Lebanon. Marine Biology 38:315-325.

Tilman, D. 1977. Resource competition between planktonic algae: an experimental and theoretical approach. Ecology 58:338-348.

- 1982. Resource competition and community structure. Princeton University Press, Princeton, N.J.

- 1994. Competition and biodiversity in spatially structured habitats. Ecology 75:2-16.

Totaro, S. 1989. Mutual shading effect on algal distribution: a nonlinear problem. Nonlinear Analysis, Theory, Methods and Applications 13:969-986.

Townsend, D. W., M. D. Keller, M. E. Sieracki, and S. G. Ackleson. 1992. Spring phytoplankton blooms in the absence of vertical water column stratification. Nature (London) 360:59-62.

Viner, A. B., and L. Kemp. 1983. The effect of vertical mixing on the phytoplankton of Lake Rotongaio (July 1979-January 1981). New Zealand Journal of Marine and Freshwater Research 17:407-422.

Visser, P. M., B. W. Ibelings, B. Van der Veer, J. Koedood, and L. R. Mur. 1996. Artificial mixing prevents nuisance blooms of the cyanobacterium Microcystis in Lake Nieuwe Meer, The Netherlands. Freshwater Biology 36: 435-450.

Walsby, A. E., and A. R. Klemer. 1974. The role of gas vacuoles in the microstratification of a population of Oscillatoria agardhii var. isothrix in Deming Lake, Minnesota. Archiv für Hydrobiologie 74:375-392.

Weissing, F. J., and J. Huisman. 1994. Growth and competition in a light gradient. Journal of Theoretical Biology 168:323-336.

Williams, L. 1964. Possible relationships between plank- 
ton-diatom species numbers and water-quality estimates. Ecology 45:809-823.

Yin, K., P. J. Harrison, R. H. Goldblatt, and R. J. Beamish. 1996. Spring bloom in the central strait of Georgia: interactions of river discharge, winds and grazing. Marine Ecology Progress Series 138:255-263.

Yount, J. L. 1956. Factors that control species number in Silver Springs, Florida. Limnology and Oceanography 1:286-295.
Zohary, T. 1985. Hyperscums of the cyanobacterium Microcystis aeruginosa in a hypertrophic lake (Hartbeespoort Dam, South Africa). Journal of Plankton Research 7:399-410.

Zohary, T., and C. M. Breen. 1989. Environmental factors favoring the formation of Microcystis aeruginosa hyperscums in a hypertrophic lake. Hydrobiologia 178: 179-192.

Associate Editor: Mathew Leibold 